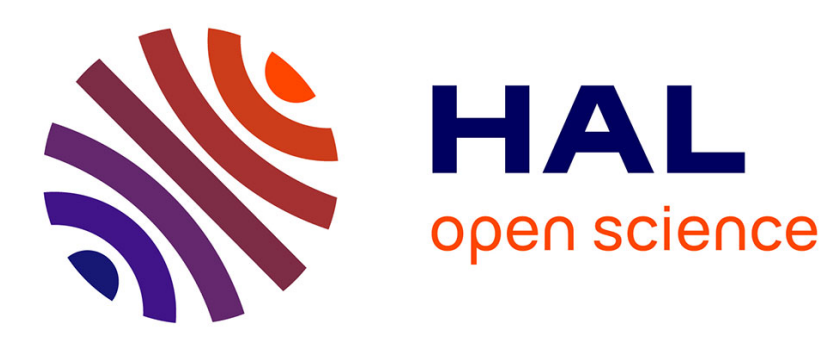

\title{
GVCs and the Endogenous Geography of RTAs
}

Lionel Fontagné, Gianluca Santoni

\section{- To cite this version:}

Lionel Fontagné, Gianluca Santoni. GVCs and the Endogenous Geography of RTAs. 2018. hal01763563

\section{HAL Id: hal-01763563 \\ https://hal.science/hal-01763563}

Preprint submitted on 11 Apr 2018

HAL is a multi-disciplinary open access archive for the deposit and dissemination of scientific research documents, whether they are published or not. The documents may come from teaching and research institutions in France or abroad, or from public or private research centers.
L'archive ouverte pluridisciplinaire HAL, est destinée au dépôt et à la diffusion de documents scientifiques de niveau recherche, publiés ou non, émanant des établissements d'enseignement et de recherche français ou étrangers, des laboratoires publics ou privés. 


\section{GVCs and the Endogenous Geography of RTAs}

Lionel Fontagné \& Gianluca Santoni

\section{Highlights}

- There has been considerable attention paid to the endogenous nature of regional trade agreements. Geography, economic size, or common history help predicting signed agreements.

- Recent developments in terms of structural gravity help clarifying this debate by taking account of all theoretically relevant determinants of bilateral trade, as well as general equilibrium effects of signing an agreement.

- We estimate the time-varying probability for a country pair to sign a trade agreement and build upon structural gravity in general equilibrium to determine how the patterns of Global Value Chains shape the evolving geography of optimal trade agreements. 


\section{Abstract}

There has been considerable attention paid to the endogenous nature of regional trade agreements Geography, economic size, or common history help predicting signed agreements. However, not all signed RTAs are "natural" according to economic determinants, as trade negotiations can be used as a tool of external policy. Recent developments in terms of structural gravity help clarifying this debate by taking account of all theoretically relevant determinants of bilateral trade, as well as general equilibrium effects of signing an agreement. Indeed, the endogeneity of trade arrangements has a time dimension and is related to firm strategies. These are the two mechanisms addressed in this paper. We estimate the time-varying probability for a country pair to sign a trade agreement and build upon structural gravity in general equilibrium to determine how the patterns of Global Value Chains shape the evolving geography of optimal trade agreements. Our results confirm that the endogenous geography of RTAs is shaped by the development of GVCs.

\section{Keywords}

Preferential Trade Agreements, Global Value Chains, Structural Gravity.

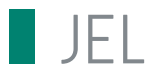

F13, F14, F16

\section{Working Paper}

\section{CEPI}

CEPII (Centre d'Etudes Prospectives et $d^{\prime}$ 'Informations Internationales) is a French institute dedicated to producing independent, policyoriented economic research helpful to understand the international economic environment and challenges in the areas of trade policy, competitiveness, macroeconomics, international finance and growth.
CEPII Working Paper

Contributing to research in international economics

(c) CEPII, PARIS, 2018

All rights reserved. Opinions expressed in this publication are those of the author(s) alone.

$\begin{array}{ll}\text { Editorial Director: } & \text { CEPII } \\ \text { Sébastien Jean } & \text { 20, avenue de Ségur } \\ & \text { TSA 10726 } \\ \text { Production: } & 75334 \text { Paris Cedex } 07 \\ \text { Laure Boivin } & +33153685500 \\ & \text { www.cepii.fr } \\ \text { No ISSN: } 1293-2574 & \text { Press contact: presse@ }\end{array}$




\section{GVCs and the Endogenous Geography of RTAs ${ }^{1}$}

Lionel Fontagné*

Gianluca Santoni

\section{Introduction}

Country-pairs self select in Regional Trade Agreements (RTAs). Membership of the same economic union facilitates trade between Germany and France, but these two large and adjacent countries have anyway characteristics making them natural trading partners. We know since Baier and Bergstrand (2004) that this endogeneity of RTAs is biasing downwards the impact of RTAs as estimated within a gravity framework. Baier and Bergstrand (2007) suggest using country-time fixed effects and dyadic effects to address this issue. Vicard (2011) adds interactions between the RTA dummy and time-varying country characteristics.

Beyond their impact on bilateral trade flows within the integrated region, determinants of trade agreements have also a multilateral dimension (Anderson and Van Wincoop, 2003). A recent strand of literature shedding light on such general equilibrium effects of RTAs and associated welfare effects (Egger et al., 2011) .

But since intermediate goods travel to their final destination through countries operating transformation before final assembly and consumption (Johnson and Noguera, 2012a), the fragmentation of production processes should help predicting the geography of regional agreements. Activity within international value chains, as measured with world input-output data, is redrafting the endogenous geography of RTAs. In other words, the optimal allocation of tasks by multinational

\footnotetext{
${ }^{1}$ We are grateful to Mario Larch and Yoto V. Yotov for helpful suggestions. We thank participants from Roma Tre University, CEPII and the MENA WTO chair for insightful comments. The usual disclaimer applies.

*PSE - Université Paris I \& CEPII, Centre d'Economie de la Sorbonne, 106-112 Boulevard de l'Hôpital, F-75647 Paris Cedex 1 (lionel.fontagne@univ-paris1.fr)

†CEPII, 20, avenue de Ségur 75007 Paris (gianluca.santoni@cepii.fr)
} 
firms contribute shaping the patterns of international trade and we can observe the statistical footprint of this in the geography of regional agreements. ${ }^{2}$

If RTAs are endogenously determined by country-pair-time characteristics, their occurrence can be predicted. Unpredicted actual RTAS must proceed from "non-economic" determinants - firstly international politics. The first aim of this paper is to operationalize an empirical framework aiming to predict which country-pairs will enter into a RTA based solely on economic and geographic determinants. Unpredicted agreements are those RTAs signed for "non-economic" purposes. ${ }^{3}$ By the same token, we also identify which country-pairs should enter into a RTA based on economic and geographic determinants, although they refrained to do so. Here again non-economic determinants (stricto sensu, e.g. legal systems) play a role that can be identified.

Indeed country-pair characteristics used to predict the occurrence of a regional agreement are time-varying. Accordingly the probability of entering into an agreement for a given country pair is varying as well. Mexico, for instance was not such "natural" partner for the US from the onset, due to its small initial economic size. However, trade integration between the two countries has increased over time the probability of Mexico and the US of signing an agreement. The second aim of our paper is to carefully take on board this time dimension in the analysis when computing the probability for two countries of entering into a trade agreement. Economic geography is changing over time, and the map of natural trading regions has to be re-drafted accordingly.

Our findings suggest that international fragmentation of production along Global Value Chains (GVCs) significantly affects the probability for country-pairs of entering into a trade agreement: to some extent, microeconomic decisions made by firms optimizing their supply chain is shaping the geography of natural trading regions. Based on our predicted geography of RTAs, we detect country-pairs that did not enter into a trade agreement and should, based on economic determinants, but also RTAs at odds with economic factors. In the latter case, political reasons have contributed shaping the observed geography of agreements. Signing - or not signing - has implica-

\footnotetext{
${ }^{2}$ Egger et al. (2008) is a first attempt to introduce the role of multinational and intra-industry trade as determinants of self-selection in regional trade agreements, although they did address the fragmentation of value chains just as an interpretation of intra-industry trade in intermediate goods within industries.

${ }^{3}$ This contrasts with Egger et al. (2011) who integrate economic as well as political determinants in their prediction concerning the formation regional agreements
} 
tions for the countries involved in the trade agreements, and by the same token on third countries, which finally has a feed-back on signing countries. Results from our general equilibrium structural gravity estimation confirm a dynamic positive effect on participants' exports and real GDP from agreements based on "non-economic" determinants. Countries sign based on non-economic determinants and start developing trade relationships making the agreement endogenously more desirable. Finally, our results indicate that there is room from additional gains from integration with China, mainly due to the development of GVCs this country is involved in.

Gravity models in a general equilibrium framework have been extensively used to perform counterfactual analysis of trade agreements. Recent contributions include e.g. Anderson and Yotov (2010), Egger and Larch (2011), Costinot et al. (2012), Eaton et al. (2012), Arkolakis et al. (2013), Behrens et al. (2014), Caliendo and Parro (2015), Heid and Larch (2016) or Mayer et al. (2018). ${ }^{4}$ Similarly, as trade costs and just-in-time strategies should involve geographically proximate countries in fragmented production processes, the regional nature of GVCs has been clearly identified, as well as their increasingly global patterns (Johnson and Noguera, 2012b, Los et al., 2015, Amador and Cabral, 2017). Our contribution to the literature is firstly to systematically identify deviations from RTA membership predicted on economic grounds, including GVCs, in a dynamic setting. Our second contribution is to provide an assessment of the economic costs and benefits of amending the observed geography of RTAs in order to fit the predictions optimizing the trade-off between sensitivity (correctly predicting the observed RTAs) and specificity (resp. their absence)of the model. To our knowledge we are the first to provide such analysis based on a structural gravity framework accounting for general equilibrium effects.

The rest of the paper is organized as follows. Data is presented in the first section. Section 2 details the empirical strategy used to predict the probability of country pairs of entering into regional trade agreements, based on economic determinants including the participation in regionally fragmented value chains. Section 3 proposes a strategy to quantify the welfare changes associated with an alternative geography of RTAs, by relying on a structural gravity system. The last section concludes.

\footnotetext{
${ }^{4}$ See Yotov et al. (2017) for an overview.
} 


\section{Stylized Facts}

We start by putting numbers on the evidence of increasing regionalism. In the WTO parlance, regional trade agreements (RTAs therafter) are stricto sensu defined as reciprocal trade agreements between two (or more) countries. Free trade agreements, customs unions or economic unions are different types of RTAs. Indeed, the depth of these agreements has a large variance, covering or not questions going beyond trade in goods. RTAs differ from Preferential Trade Agreements (PTAs) corresponding to unilateral trade preferences schemes (e.g. the Generalized System of Preferences). In the following, we adopt this definition and restrict our analysis to RTAs as defined by the WTO. ${ }^{5}$

The first evidence on RTAs is the surge of new agreements in the 1990 s depicted in figure $1 .{ }^{6}$ The recently notified agreements in force go much beyond what one could consider as natural trading regions. While an agreement signed in June 2014 between the EU and Ukraine sounds like a "natural" trading region, the agreements between Canada and Jordan (October 2012), or Iceland and China (July 2014) hardly fit such criterion. A complex set of determinants must be at play.

In figure 2 we now consider the country-pair dimension of regionalism that will be used in our estimation strategy and plot the share of the $0.5 \times 159 \times 158$ country pairs covered by an active (i.e. signed and ratified ) RTA at each date from 1995 on. ${ }^{7}$ We consider the stock of country pairs involved in an RTA in force at each date, not the flow of newly acceding country pairs. We disregard country pairs involved in notified RTAs not in force. Out of the 159 member countries of the WTO, the share of pairs covered by an agreement has tripled within two decades. We also plot the share computed on the restricted sample used below in our econometric exercise due to data availability (we have to rely on UNIDO data for certain variables afterwards): the evolution is similar although the share of country pairs engaged in RTAs is slightly larger with this reduced sample.

\footnotetext{
${ }^{5}$ We rely on the CEPII database which is taking integrating RTA data from the WTO published in 2015.

${ }^{6}$ RTAs are notified separately for goods and/or services but we consider here the number of new "physical" agreements in force, meaning that data for goods and services is consolidated.

${ }^{7}$ Notice that the number of country pairs is varying over time over the long period considered here; thus it is preferable to use shares.
} 
Figure 1 - Number of new RTAs in force (net), by year

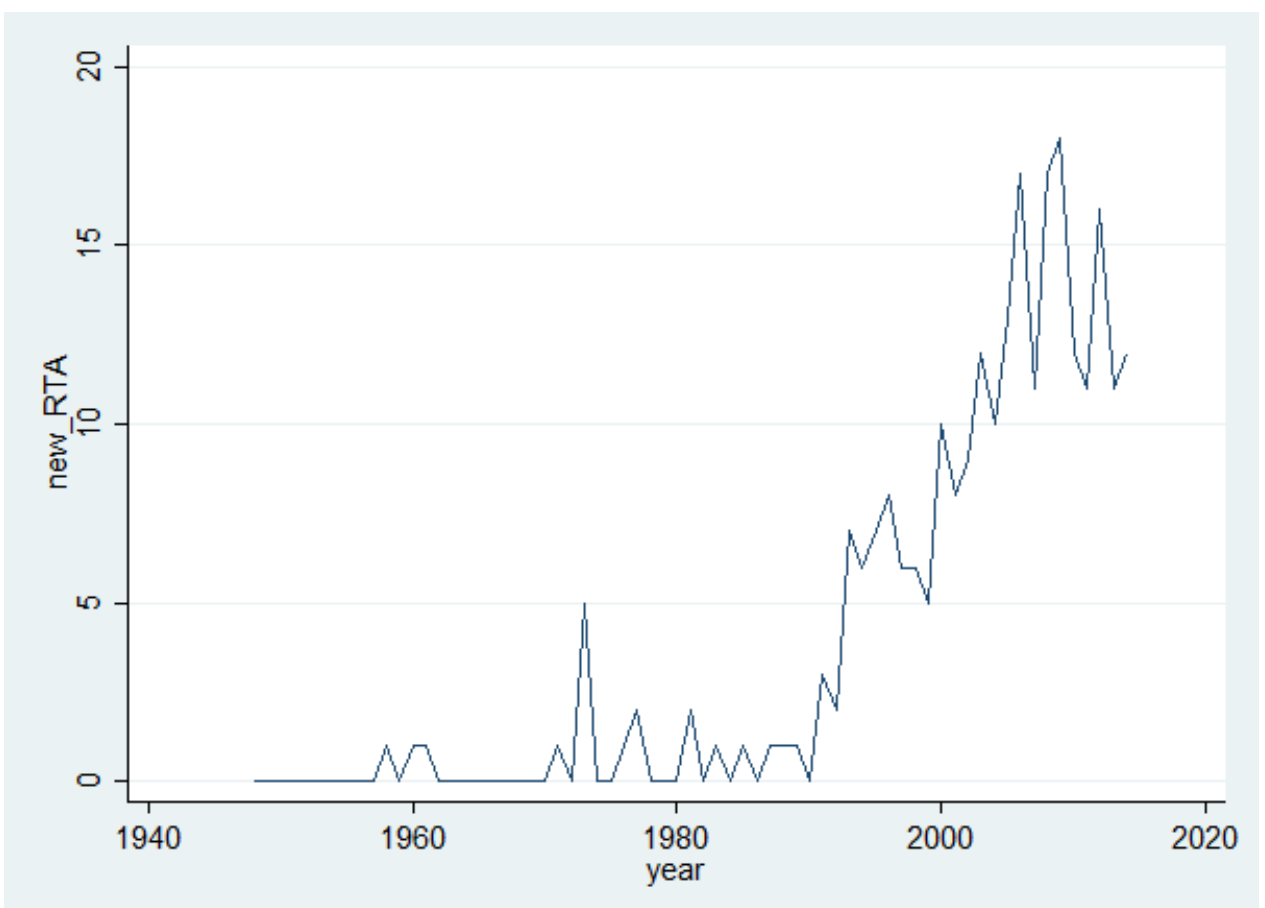

Source: WTO, Regional Trade Agreements Information System (RTA-IS). RTAs in goods or services.

Figure 2 - Share of country pairs involved in a RTA by year

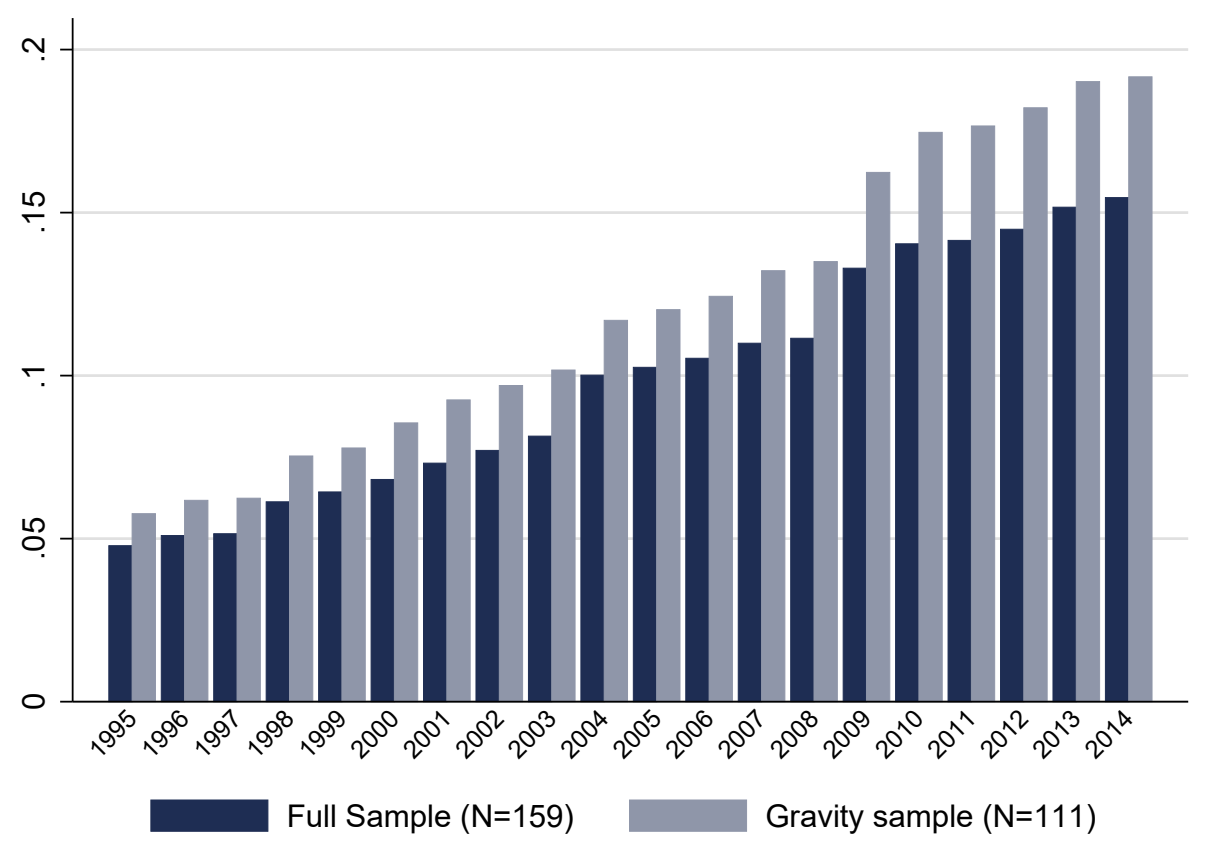

Note: Data on preferential trade agreements are from the CEPII gravity database, see Head and Mayer (2014). 


\section{Empirical Strategy}

The aim of this section is to operationalize a consistent empirical framework, taking stock of theory-based advances in the design of gravity equations. The challenges are first to account for reverse causality, second to take on board the multilateral effects and third to account for the international fragmentation of production.

Reverse causality is addressed by controlling for five-year lagged usual economic determinants of the formation of trade agreements. The economic determinants that we include in our framework follow Baier and Bergstrand (2004) and Baier et al. (2014), and we add a control for the degree of fragmentation of value chains among each pair of countries.

Multilateral effects are considered in terms of distance (vis-à-vis the rest of the world for each country pair) and comparative advantage. Gravity forces related to monopolistic-type trade models have finally to be considered (size and similarity in size) in relation to the demand for variety (Helpman, 1987).

The involvement of the country pair in Global Value Chains (GVCs) is measured using the concept of value added income. The GVC income decomposition (Timmer et al., 2013), traces the origin of value added embedded in final goods and services, identifying the value added contribution of each country that is involved in domestic production. Considering that value added is ultimately the remuneration of production factors (i.e. capital and labor) the decomposition allows to track and allocate the income generated through a given value chain to the different countries involved in the different stages of production. ${ }^{8}$

We estimate such equation using data for the period 1990-2014 while introducing a five-year lag for covariates (meaning that we are ultimately considering agreements signed between country pairs over the period 1995-2014). Most of the covariates that we introduce are significant and we

\footnotetext{
8Taking the example from (Timmer et al., 2013): "Demand for German cars will in the first instance raise the output (and income) of the German car industry. But production in this industry relies on car parts and components that are produced elsewhere, such as engines, braking systems, car bodies, paint, seat upholstery or window screens, but also energy, and various business services such as logistics, transport, marketing and financial services. These intermediate goods and services need to be produced as well, thus raising output (and income) in the industries delivering these, say the German business services industry, the Czech braking systems industry and the Indian textile industry" (Italics added).
} 
project the probability of signing an agreement based on these economic determinants. The derived predicted probability of observing an agreement between country $i$ and country $j$ being based only on economic fundamentals, we conversely interpret RTAs with low probabilities as those signed mostly based on non-economic (i.e. political) reasons.

The last step of the reasoning is to have a metric of associated welfare gains, accounting for the above mentioned general equilibrium effects. To proceed, we apply the general equilibrium gravity estimation, proposed Anderson et al. (2016). The multilateral resistance terms in the structural gravity equation (Anderson and Van Wincoop, 2003) offer a good metric of the general equilibrium of trade costs, as they account not only for the changes in bilateral trade costs, but also for the change in trade costs vis-a-vis third countries. Under the usual assumptions on the global market clearance and the countries' budget constraint, the multilateral resistance terms are the solution of a non-linear set of equation systems.

However, instead of solving the system, one can rely on the property shown by Fally (2015): the multilateral resistance terms are exactly equal to the fixed effects of the structural gravity equation, when estimated with Poisson Pseudo Maximum Likelihood (PPML). The method proposed by Anderson et al. (2016) implements this solution. The same idea applies to the counterfactual, whereby the system is re-estimated, instead of being solved, with the alternative trade frictions. Interestingly, changes in multilateral resistance terms can be derived from changes in the fixed effects, changes in exports and changes in consumption in order to measure welfare change for each country. ${ }^{9}$ We will apply this method and compute the welfare changes associated with an alternative geography of RTAs.

The rest of this section is organized as follows. We start by evaluating the contribution of economic determinants to the probability of being member of an RTAs for any pair of country in the world. Among these determinants, we account for the international fragmentation of production and control for the lagged bilateral production linkages between exporter and importer. We then predict the occurrence of RTAs.

\footnotetext{
${ }^{9}$ Using a benchmark exercise of abolishing the border effects for manufactured products, Anderson et al. (2016) demonstrate that the obtained changes are in line with those provided when solving the model with Matlab.
} 
Indeed the model can correctly predict existing or absent agreements, but it may also predict wrongly existing agreements (wrongly predicting an absence of agreement is less a problem). What is driving the quality of the prediction is the chosen probability cut-off. With a probability of 1 , there is nothing like an RTA to be observed, and reciprocally with a very small probability. The capacity of predicting signed agreements increases quasi-linearly with the decrease in the probability cut-off, whereas capacity to predict the absence of agreement is good even for very small probabilities. There is accordingly a trade off between predicting correctly one type of outcome (signing) and the other one (not signing). We will adopt a simple criterion maximizing the quality of the prediction and retrieve the impact of RTAs on trade under such circumstances. The so-identified missclassified RTAs from the probabilistic model will be used in a structural gravity system to evaluate the welfare changes associated with alternative sets of trade agreements in the next section.

\subsection{GVCs Shaping the Geography of RTAs}

The aim of this section is to identify how economic determinants shape the observed RTAs, considering all possible pairs of countries. We neither address the perimeter of any RTA (i.e. which series of countries did actually sign in), nor the depth of the signed RTAs (e.g. existence of a provision on services or competition). We simply ask whether exporter $i$ and importer $j$ belong to the same RTA at time $t$ and how economic determinants affect this probability, including the connection of $i$ an $j$ through the fragmentation of value chains.

A potential concern is that bilateral trade intensity and involvement in common value chains might not be orthogonal: we address this problem by takin the lagged involvement in value chains and by checking that the residuals of two equations of interest - signing an agreement and amount of trade - are not correlated.

One pending question is whether participation of $i$ or $j$ to a series of other RTAs is affecting the probability of signing in another agreement. By the same token, participation of the Rest of the World might impact the probability of $i$ and $i$ of embarking in a new agreement. We will tentatively control for these two possible third-country effects also.

We follow the specification in Baier and Bergstrand (2004), Egger and Larch (2008) and Baier 
et al. (2014) to evaluate the contribution of economic determinants to the probability of RTA formation. Our dependent variable is $R T A_{i j t}$ taking the value of 1 if country $i$ and country $j$ are member of the same preferential agreement at time $t$ and zero otherwise ${ }^{10}$. The baseline specification reads as follow:

$$
R T A_{i j, t}=\Gamma_{i j, t-5} \cdot \beta+\bar{\Gamma}_{i j} \cdot \bar{\beta}+\sum_{k=1}^{6} \delta_{k}+\epsilon_{i j, t}
$$

Where the vector $\Gamma$ includes the main bilateral economic determinants of trade agreements as identified by previous studies: Natural $l_{i j}$ is the log of the inverse of the distance between $i$ and $j$; Remote $_{i j}$ measures the average log distance of country $i$ and $j$ from all the other trading partners. ${ }^{11} G D P_{i j, t-5}^{s u m}$ is the log of the sum of countries GDP aiming to capture their market size; $G D P_{i j, t-5}^{s i m}$ captures the similarity in the two market size; $D K L_{i j, t-5}$ is the absolute difference in the (log) real per capita GDP, aiming to capture difference in the factor endowment between country $i$ and $j$; SQDK $L_{i j, t-5}$ is the squared factor endowment and DROWK $L_{i j, t-5}$ is the absolute difference in factor endowment between the ij pair and the rest of the world. We also have to control for the involvement of each country in the $i, j$ pair in RTAs with third countries, just because signing a further RTA reduces for $i$ the benefit of the existing RTAs it signed, as a result of general equilibrium effects, and similarly for $j$. We introduce two variables tentatively capturing these effects: $M R T A_{i, t-5}$ and $M R T A_{j, t-5} . M R T A_{i, t-5}$ is a multilateral indexes of country i's agreements with all other countries (excluding $j$ ); This is the (five-year lagged) stock of signed agreements by $i$. MRT $A_{j, t-5}$ is the equivalent for country $j$. We finally introduce a variable accounting for the overall (lagged) presence of signed agreements in the world economy, excluding those signed by $i$ and $j$ : ROWRT $A_{j, t-5}$. The latter variable controls for the total number of country pairs involved in a trade agreement (excluding $i$ and $j$ ). ${ }^{12}$

Moreover, we also include a control for lagged bilateral production linkages, $G V C_{i j, t-5}^{i n c o m e}$, computed as the log of value added flows between country pairs. This variable measures the amount of

\footnotetext{
${ }^{10}$ As in Baier and Bergstrand (2004) and Egger and Larch (2008) the outcome of $R T A_{i j}$ may be interpreted as the difference in unobserved utility between the two outcomes: membership vs non-membership.

${ }^{11}$ When $i$ and $j$ belong to different continents Remote $_{i j}$ is equal to zero

${ }^{12} \mathrm{~A}$ detailed description of the variables is reported in the Annex 6.1.
} 
income that is generated through the supply chain connecting country $i$ and country $j$. Following Johnson (2017) the GVC income decomposition for a given year $t$ can be formalized as:

$$
G V C_{i k j s}=V *(I-A)^{-1} * F
$$

Where $V$ is a diagonal matrix of value added to output ratios; $A$ is the technical coefficient matrix, whose general entry $a_{i k j s}$ gives the input share of country-industry $i k$ used in the production of country-industry js. The $(I-A)^{-1}$ being the Leontief inverse ; whereas $F$ is a diagonal matrix of world final demand. The general entry of the resulting $G V C_{i k j s}$ matrix measures the value added in country $i$ and sector $k$ that is related to production of industry $s$ in country $j$; in the following application we aggregate the sectoral dimension resulting in country-by-country matrix $G V C_{i j}$. Notice that so doing we account for indirect trade in services as well, as we do not restrict the computation to manufacturing sectors. The calculation of Equation 2 relies on the multi-region input-output data from the EORA MRIO database. ${ }^{13}$

$\overline{\Gamma_{i j}}$ includes the average of each covariate by country pairs in order to control for the possible correlation of time-variant variables with unobserved time-invariant heterogeneity (see Wooldridge (2010)). Finally, $\delta_{k}$ represent a set of fixed effects for the following sub-periods: 1995-1998, 1999-2001, 2002-2004, 2005-2007, 2008-2011, 2012-2014.

Figure 3 reports some preliminary evidence on the positive association between value added trade and PTA, confirming that the bulk of GVC trade occurs between countries with a preferential trade agreement in place.

Table 1 reports the estimated coefficients of the across different probability models and by subperiods. In line with the previous literature, our preferred specification employ a logit estimator but we also report results from probit. The overall sample covers $N(N-1) / 2$ possible pairs for each year, where $N=159$ countries $^{14}$.

\footnotetext{
13 The EORA database is the most complete source of information on countries production structure and input-output (IO) tables, covering for 189 countries (plus a rest of the world aggregate) and 26 industries for the period 1990-2015. For further information, see Lenzen et al. (2012) and Lenzen et al. (2013). For a recent application of EORA to quantify welfare effects of trade liberalization see Caliendo et al. (2015).

${ }^{14}$ Note that when including the GVC variables the sample size shrinks due to the fact that few countries included in
} 
Figure 3 - Distribution of GVC income flows

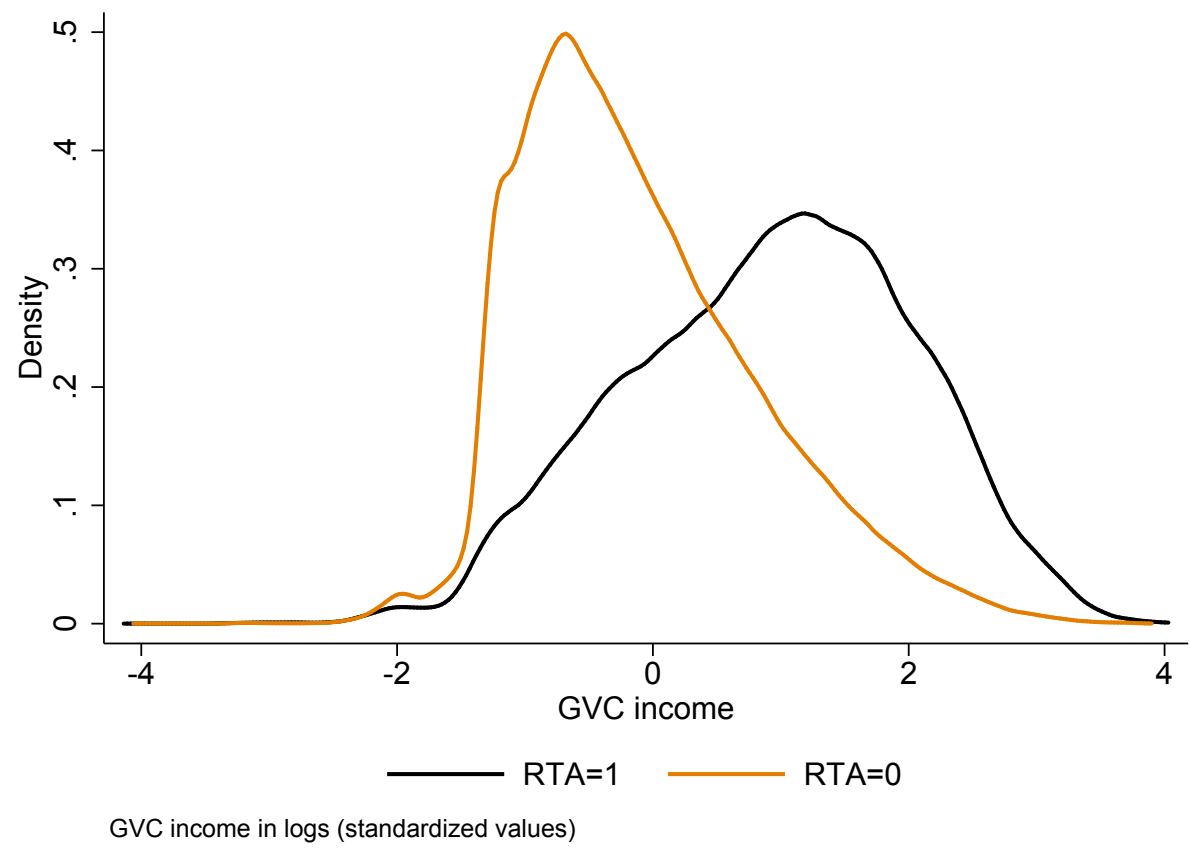

Note: The two graphs report the distribution of $\log ($ GVCincome) for country pairs with a preferential trade agreement, i.e. $R T A=1$, versus country pairs without trade agreements, i.e. RTA $=0$. Before computing the density distribution the values of $\log$ (GVCincome) have been standardized to a zero mean and standard deviation equal to 1. Note that the observations are pooled together over the full sample period: 1995-2015.

Using the Logit estimator and considering the parameter associated with Natural ${ }_{i j}$, we firstly observe that proximate countries are more prone to sign a trade agreement, being "natural trading partners" in line of Krugman (1991)'s argument about transport costs. This is reinforced by remoteness of the two trading partners from the rest of the world (resp. Remote $e_{i j}$ ). Large countries of similar size are more prone to sign an agreement because this is how trade in horizontally differentiated varieties is maximized (Helpman, 1987), as shown respectively by the parameter estimates for $G D P_{i j, t-5}^{s u m}$ and $G D P_{i j, t-5}^{s i m}$. The intensity of the comparative advantage $\left(D K L_{i j, t-5}\right.$ is a rough proxy for differences in factor endowments and or technology between the two partners) helps predicting the occurrence of a trade agreements between the two considered countries, and the curvature of this relationship is given by $S Q D K L_{i j, t-5}$.

Finally and importantly, country pairs linked by existing value chains are more prone to enter into a regional agreement $\left(G V C_{i j, t-5}^{i n c o m e}\right)$.

Next, we can split the sample into three sub-periods instead of considering the whole period with the main sample are not covered in the EORA dataset, namely: VCT, LCA, GNQ, GNB, COM. 
sub-period fixed effects. Results indicated in the three last columns of table 1 point to profound changes in the international trade patterns. First and foremost, we observe that the depth of global value chains has an increasing predicting power over time: regional integration is increasingly shaped by regional chains (see coefficients on $G V C_{i j, t-5}^{i n c o m e}$ in columns 4-6). The same comments apply to distance: Natural ${ }_{i j}$ and Remote $_{i j}$ play an increasing role. Interestingly, proximity plays an increasing role, even controlling for the toll taken by distance on the functioning of global value chains. This increasing role of distance was somehow unexpected given the decreasing transportation costs, the reduction in trade barriers and the reduction in communication costs more generally. This result is echoing the non-decreasing parameter estimated on distance in a gravity equation having bilateral trade as a dependent variable. It has been interpreted as the "distance puzzle". ${ }^{15}$ Using a structural gravity model Yotov (2012) suggests there is no puzzle when the gravity equation is correctly specified and includes domestic flows. The effects of globalization are spread evenly across bilateral pairs and then cannot be captured as long as domestic flows are not used as a benchmark. In contrast, globalization has to be measured as the increase in international trade flows compared to internal flows. ${ }^{16}$ This is the approach we will embrace below.

Contrasting with this increasing proximity, the third sub-period points to a reversal of the usual determinant associated with the monopolistic competition trade model: GDP $P_{i j, t-5}^{s i m}$ reduces the probability of entering into a regional trade agreement in the last sub-period (2008-14). Such outcome cannot be over-interpreted anyway, as most agreements with "obvious" trading partners were already signed before the 2008 crisis. Hence, predicting the newly signed agreements must resort to other determinants than two-way trade in horizontally differentiated products between similar countries of large size (think of France and Germany for instance).

We previously stressed that multilateral effects could play a role: does the stock of signed agreements by any of the two partners $i$ and $j$ affect the probability of the two entering into an RTA? The answer, provided by the parameter estimated on $R T A_{j, t-5}$ is that this multilateral effect slightly increases (and not decreases as one should have expected in presence of general equilibrium effects)

\footnotetext{
${ }^{15}$ Based on a meta-analysis of a hundred of papers and 1,467 estimated distance effects, Disdier and Head (2008) show that the negative impact of distance of trade remained persistently since the middle of the XXth century: bilateral trade is nearly inversely proportionate to distance.

${ }^{16}$ Recall that we are not explaining trade here, but the occurrence of bilateral trade agreements.
} 
the probability of signing an agreement between $i$ and $j$. This effect is not very robust however as shown for the sub-periods in the three last columns of table 1 . And the positive impact could be interpreted as economies of scope in the negotiation of RTAs. The EU for instance, is working with a template of the RTA to be signed in many cases. We also wanted to double check that the overall dynamics of regional integration in the world economy was not the main driver of our results: we observe that ROWRT $A_{i j, t-5}$ has no impact on our outcome of interest.

A point of potential concern of introducing GVCs in the probabilistic model 1 is related to the fact that the depth of GVCs may be capturing the intensity of bilateral trade flows. To address this issue, we regress separately the bilateral intensity of GVCs and the value of bilateral trade on our set of independent variables. We then correlate the residuals of the two regressions. The result is shown in Figure 4. The fitted line provides a measure of the correlation between the residuals of the two separate regressions: $G V C_{i j, t}^{i n c o m e}=\Gamma_{i j, t}+\delta_{k}+\epsilon_{i j, t}$ and $T r a d e_{i j, t}=\Gamma_{i j, t}+\delta_{k}+\varepsilon_{i j, t}$. It is clear from the graph that the correlation between the two residuals is negligible, suggesting that our GVC measure is not another metric of the intensity of bilateral trade flows. This was expected, as $G V C_{i j, t}^{i n c o m e}$ mirrors the intricate set of domestic and international input-output relations.

\section{Figure 4 - Conditional Correlation of GVC income and Bilateral Trade}

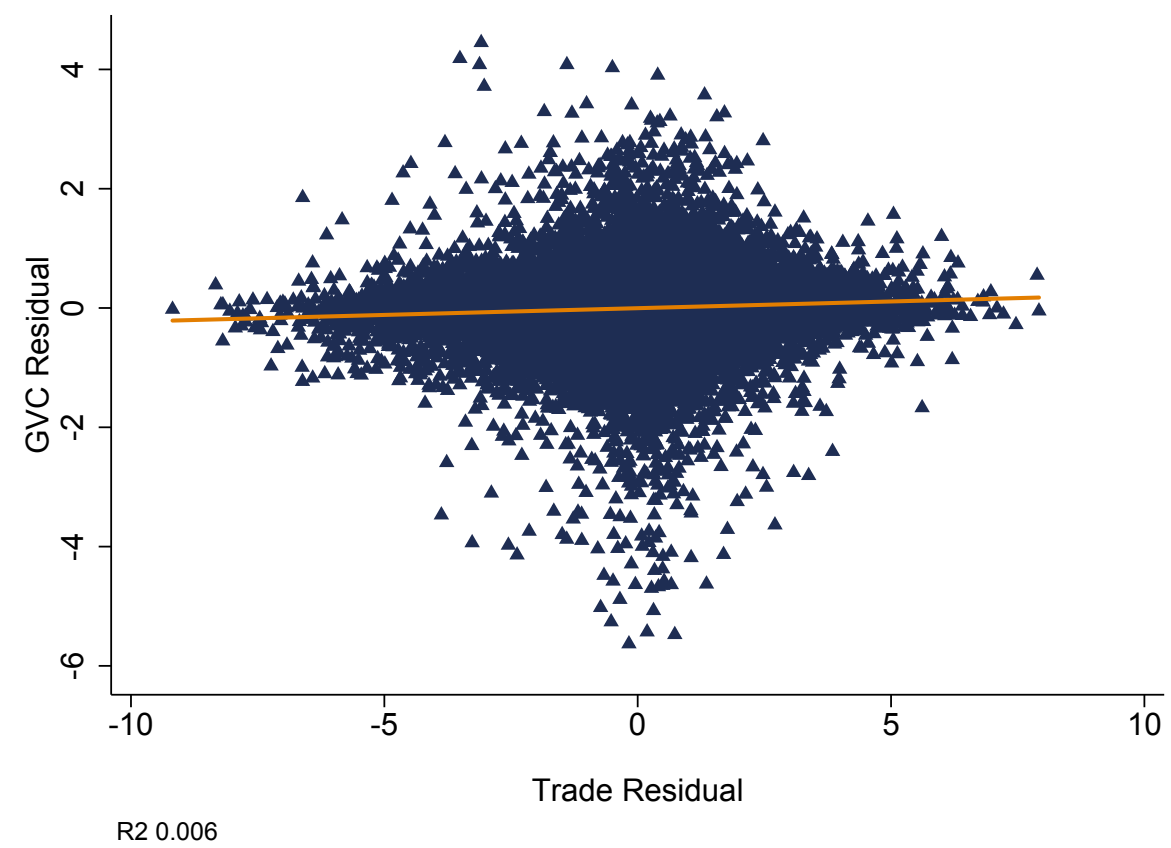

Note: linear correlation between $G V C=\log \left(G V C_{i->j, t}+G V C_{j->i, t}\right)$ and Trade $=\log \left(i m p_{i j, t}+\exp _{i j, t}\right)$ netting out the covariates of the baseline model 1 . 
Table 1 - Marginal effects for the economic determinants of RTAs

\begin{tabular}{|c|c|c|c|c|c|c|c|}
\hline $\begin{array}{l}\text { Dep Var: } \\
\text { RTA }_{i j t}\end{array}$ & $\begin{array}{c}\text { Probit } \\
(1)\end{array}$ & $\begin{array}{c}\text { Logit } \\
(2) \\
\end{array}$ & $\begin{array}{c}\text { Probit } \\
(3) \\
\end{array}$ & $\begin{array}{c}\text { Logit } \\
(4)\end{array}$ & $\begin{array}{c}\text { Logit }^{95-01} \\
(5)\end{array}$ & $\begin{array}{c}\text { Logit }^{02-07} \\
(6)\end{array}$ & $\begin{array}{c}\text { Logit }^{08-14} \\
(7)\end{array}$ \\
\hline Natural $_{i j}$ & $\begin{array}{c}0.029 * * * \\
(0.001)\end{array}$ & $\begin{array}{c}0.026 * * * \\
(0.002)\end{array}$ & $\begin{array}{c}0.035 * * * \\
(0.001)\end{array}$ & $\begin{array}{c}0.023^{* * *} \\
(0.002)\end{array}$ & $\begin{array}{c}0.010 * * * \\
(0.001)\end{array}$ & $\begin{array}{c}0.025^{* * *} \\
(0.002)\end{array}$ & $\begin{array}{c}0.039 * * * \\
(0.003)\end{array}$ \\
\hline Remote $_{i j}$ & $\begin{array}{c}0.003^{* * *} \\
(0.000)\end{array}$ & $\begin{array}{c}0.004^{* * *} \\
(0.000)\end{array}$ & $\begin{array}{c}0.002 * * * \\
(0.000)\end{array}$ & $\begin{array}{c}0.004^{* * *} \\
(0.000)\end{array}$ & $\begin{array}{c}0.002 * * * \\
(0.000)\end{array}$ & $\begin{array}{c}0.003^{* * *} \\
(0.000)\end{array}$ & $\begin{array}{c}0.007^{* * *} \\
(0.000)\end{array}$ \\
\hline $\mathrm{GDP}_{i j, t-5}^{\text {sum }}$ & $\begin{array}{c}0.003 \\
(0.002)\end{array}$ & $\begin{array}{c}0.010 * * * \\
(0.003)\end{array}$ & $\begin{array}{l}-0.003 \\
(0.003)\end{array}$ & $\begin{array}{c}0.015^{* * * *} \\
(0.004)\end{array}$ & $\begin{array}{c}0.012 * * * \\
(0.002)\end{array}$ & $\begin{array}{l}0.010^{*} \\
(0.005)\end{array}$ & $\begin{array}{c}-0.037^{* * *} \\
(0.006)\end{array}$ \\
\hline $\mathrm{GDP}_{i j, t-5}^{\operatorname{sim}}$ & $\begin{array}{c}-0.005^{* *} \\
(0.002)\end{array}$ & $\begin{array}{c}0.006 * * * \\
(0.002)\end{array}$ & $\begin{array}{c}-0.006^{* *} \\
(0.003)\end{array}$ & $\begin{array}{c}0.010 * * * \\
(0.003)\end{array}$ & $\begin{array}{c}0.007^{* * *} \\
(0.001)\end{array}$ & $\begin{array}{c}0.019 * * * \\
(0.005)\end{array}$ & $\begin{array}{c}-0.037^{* * *} \\
(0.006)\end{array}$ \\
\hline $\mathrm{DKL}_{i j, t-5}$ & $\begin{array}{l}-0.001 \\
(0.003)\end{array}$ & $\begin{array}{c}0.010 * * * \\
(0.003)\end{array}$ & $\begin{array}{c}-0.007^{* *} \\
(0.003)\end{array}$ & $\begin{array}{c}0.009 * * \\
(0.004)\end{array}$ & $\begin{array}{l}-0.000 \\
(0.001)\end{array}$ & $\begin{array}{c}0.016 * * * \\
(0.005)\end{array}$ & $\begin{array}{c}0.002 \\
(0.007)\end{array}$ \\
\hline $\mathrm{SQDKL}_{i j, t-5}$ & $\begin{array}{l}0.001 * \\
(0.001)\end{array}$ & $\begin{array}{c}-0.005^{* * *} \\
(0.001)\end{array}$ & $\begin{array}{c}0.001 \\
(0.001)\end{array}$ & $\begin{array}{c}-0.003^{* *} \\
(0.001)\end{array}$ & $\begin{array}{c}0.001 \\
(0.001)\end{array}$ & $\begin{array}{c}-0.004^{* * *} \\
(0.002)\end{array}$ & $\begin{array}{l}-0.001 \\
(0.003)\end{array}$ \\
\hline DROWKL $_{i j, t-5}$ & $\begin{array}{c}0.001 \\
(0.003)\end{array}$ & $\begin{array}{c}0.018^{* * *} \\
(0.004)\end{array}$ & $\begin{array}{c}0.015^{* * *} \\
(0.004)\end{array}$ & $\begin{array}{c}0.019 * * * \\
(0.005)\end{array}$ & $\begin{array}{c}0.005^{* * *} \\
(0.002)\end{array}$ & $\begin{array}{c}0.037^{* * *} \\
(0.008)\end{array}$ & $\begin{array}{c}0.028 * * * \\
(0.008)\end{array}$ \\
\hline $\mathrm{MRTA}_{i, t-5}$ & $\begin{array}{l}-0.000 \\
(0.000)\end{array}$ & $\begin{array}{c}0.001^{* * *} \\
(0.000)\end{array}$ & $\begin{array}{c}0.000 \\
(0.000)\end{array}$ & $\begin{array}{c}0.001^{* * *} \\
(0.000)\end{array}$ & $\begin{array}{c}-0.000 * * \\
(0.000)\end{array}$ & $\begin{array}{c}0.000 \\
(0.000)\end{array}$ & $\begin{array}{l}0.000 * * \\
(0.000)\end{array}$ \\
\hline $\mathrm{MRTA}_{j, t-5}$ & $\begin{array}{c}0.000 * * * \\
(0.000)\end{array}$ & $\begin{array}{c}0.001^{* * *} \\
(0.000)\end{array}$ & $\begin{array}{l}-0.000 \\
(0.000)\end{array}$ & $\begin{array}{c}0.001^{* * *} \\
(0.000)\end{array}$ & $\begin{array}{c}-0.000 * * * \\
(0.000)\end{array}$ & $\begin{array}{c}0.000 * * * \\
(0.000)\end{array}$ & $\begin{array}{c}0.001^{* * *} \\
(0.000)\end{array}$ \\
\hline ROWRTA $_{i j, t-5}$ & $\begin{array}{c}0.000 * * * \\
(0.000)\end{array}$ & $\begin{array}{l}-0.000 \\
(0.000)\end{array}$ & $\begin{array}{c}0.000 * * * \\
(0.000)\end{array}$ & $\begin{array}{c}-0.000 * * * \\
(0.000)\end{array}$ & $\begin{array}{c}0.000 * * * \\
(0.000)\end{array}$ & $\begin{array}{c}0.000 * * * \\
(0.000)\end{array}$ & $\begin{array}{c}0.000 * * * \\
(0.000)\end{array}$ \\
\hline $\mathrm{GVC}_{i j, t-5}^{\operatorname{lncome}}$ & & & $\begin{array}{c}0.001 * * \\
(0.001)\end{array}$ & $\begin{array}{c}0.002 * * \\
(0.001)\end{array}$ & $\begin{array}{c}0.001^{* *} \\
(0.000)\end{array}$ & $\begin{array}{c}0.002 * * \\
(0.001)\end{array}$ & $\begin{array}{c}0.006 * * * \\
(0.002)\end{array}$ \\
\hline Observations & 251220 & 251220 & 234250 & 234250 & 81594 & 70293 & 82363 \\
\hline Pseudo- $R^{2}$ & 0.483 & 0.483 & 0.504 & 0.510 & 0.526 & 0.521 & 0.486 \\
\hline Log-Likelihood & -38602 & -41834 & -35456 & -37962 & -8933 & -10983 & -17356 \\
\hline
\end{tabular}

Standard errors in parenthesis are clustered by country-pair $i j, * * * p<0.01, * * p<0.05, * p<0.1 . \overline{\Gamma_{i j}}$ and the fixed effects $\delta_{k}$ are included in all regressions but not reported. 


\subsection{Predicted probabilities of RTAs}

We can now predict the occurrence of RTAs, as determined by economic characteristics of each country pair, including joint involvement in fragmented value chains. The predicted probabilities for the whole set of country pairs involved in RTAs in the sample are reported in Figure 5. The model may correctly predict exiting agreements, may correctly predict the absence of agreement, or may wrongly predict the absence of an agreement while the agreement is actually observed for a given country pair. We accordingly define three possibilities:

- A "true positive" (TP thereafter) happens when the model correctly classify the existence of an RTA;

- A "true negative" (TN) happens when the model correctly classify the absence of an RTA;

- A "false negative" (FN) happens when the model wrongly predicts the absence of an existing agreement.

We disregard the last outcome - wrongly predicting an actually absent agreement, "false positives"

- as it shows up only exceptionally in this procedure. We will address these cases below when we build our counterfactual geography of RTAs. ${ }^{17}$

In order to evaluate the goodness-of-fit of our model we need to set a probability cut-off that allows to discriminate the percentage of correctly predicted events (a country-pair being member at a certain date of an RTA) for both outcomes (RTA=1 and RTA=0). Following Baier et al. (2014) we set the cut-off probability that maximizes both the rates of true positives and true negatives.

Table 2 reports in column (1) the number of country pairs being member on an RTA along with the unconditional probability of observing a RTAs between any two country and the number of existing linkages in each period $k$ - column (2). In general, the unconditional probability of signing a RTA between two random countries in the sample is relatively low, $9.8 \%$ over the whole period (1995-2014) but it is increasing substantially over time: from 5.9\% (1995-2001) to 13.9\% (20082014). Column (3) and (4) reports the percentage of "true positive" (TP) and the "true negatives"

\footnotetext{
${ }_{17}$ We use the "false positives" agreement with China as a special case in building one of our counterfactual scenarios.
} 
(TN) implied by the arbitrary threshold of 0.5 , often used in the literature. As pointed out by Baier et al. (2014) being member of an RTA is a relatively rare event and setting a threshold at 0.5 implies that the predictive power of the model is mostly driven by the not very informative TNs.

Figure 6 reports the response of the TP rate ("Sensitivity") and TN ("Specificity") to different probability cutoffs; in our preferred specification we set the cutoff as the one maximizing the share of true positives and true negatives ( $\mathrm{Pr}>$ Sensitivity/Specificity). ${ }^{18} \ln$ Table 2 , columns (5) to (8), we report the optimal cutoff at each period $k$ along with the percentage of TP, TN and the number of FN predicted by the model. At the optimal cutoff computed for the whole sample period, the Logit model correctly classifies over $86.4 \%$ of positive $(R T A=1)$ and $79.8 \%$ of negative $(R T A=0)$ events. The share of miss-classified newly signed RTAs, i.e. False Negatives $(F N)$ and False Positives $(F P)$, is reported in column 8 and 9 of Table 2. Column 8 reports the number of country pairs that ratified an RTA not driven by strong economic determinants, i.e. $\operatorname{pr}(\mathrm{RTA})<$ cutoff. $^{19}$ Column 9 reports instead the number of countries that should sign a trade agreement with China, but did not yet, i.e. $\operatorname{pr}(\mathrm{RTA})>$ cutoff. In Section 3 we use such miss-classified RTAs as two separate trade policy shocks in the structural gravity estimation.

Before turning to the general equilibrium analysis we provide a graphical evidence on the distribution of China optimal trade partners. Figure 7 reports countries that should sign (but have not) an RTA with China according to model 1. The figure compares two periods, 1995-2001 and 2008-2014, and the colors indicate the probability of signing, the highest probabilities corresponding to the darkest nuance. Two conclusions can be drawn from this comparison. Firstly, the increasing integration of China in the world economy raised the expected probability of signing an RTA with China for several countries. These countries are not necessarily close to China, suggesting that economic determinants play a big role, beyond distance, and that value chains are increasingly global. Interestingly, several of the new "natural" partners of China are in Europe

\footnotetext{
${ }^{18}$ As in Baier et al. (2014) the optimal threshold is close to the unconditional probability of the event.

${ }^{19}$ Note that in the structural gravity estimation the sample size is reduced to 111 countries and only 21 European Countries are included (i.e. the Czech Republic, Estonia, Hungary, Lithuania, Luxembourg, Latvia, Slovakia are dropped due to the lack of intra-national trade flows). As an example, the agreement between EU and Chile (period 2002-2007) is classified as a false negative for all the 21 individual countries in the sample, whereas the one between EU and Peru (period 2008-2014) is above the threshold only for Slovenia. Moreover, in Table ST1 in the Annex 6.2 we report the results from the regression of the residuals of Equation 1 on a series of institutional political variables. Results confirms that residuals from the logit regression strongly correlates with these "non-economic" variables.
} 
(e.g. Spain, Germany, France, the United Kingdom or Sweden). ${ }^{20}$ Mexico or Morocco also enter in the list, among others. Interestingly, some "natural" partners disappear. This should not come as a surprise: as already stressed, trade costs have a general equilibrium element. An increased economic proximity of certain countries with China, translates into an increased relative distance vis-à-vis other countries. The emblematic example of such third-country effect is India, present in the list of expected RTAs with China in the first period, but no longer in the second. The second conclusion that can be drawn from this exercise is related to the contribution of the development of GVCs to the reshaping of the international geography of RTAs. We can now provide a more substantive illustration of the arguments referred to above, by plotting in Figure 8 the distribution of China's optimal trade partners in the last period of our sample, with (upper panel) and without (lower panel) the contribution of GVCs. ${ }^{21}$ A visual inspection illustrates our claim that most of the reshaping of the international geography of RTAs is driven by the development of GVCs.

Figure 5 - Frequency of RTAs predicted probabilities

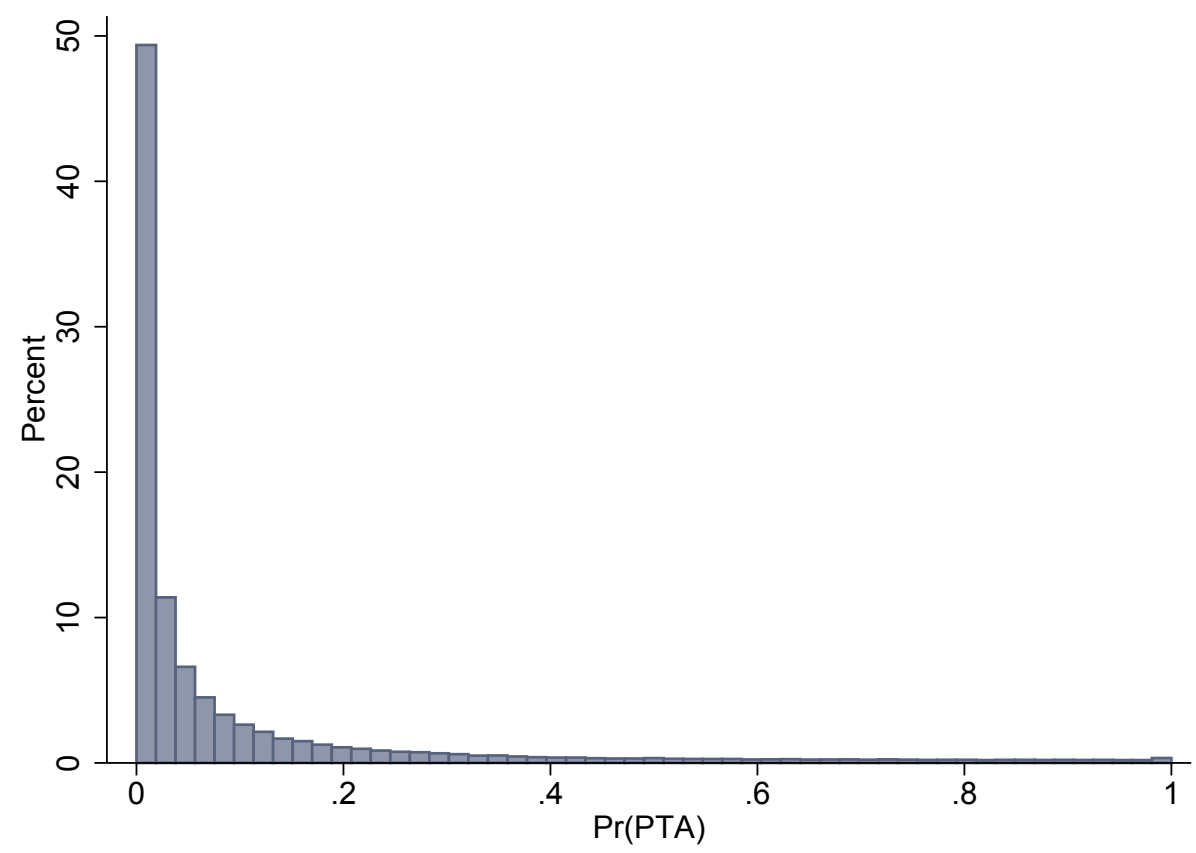

Note: PTAs Probabilities are obtained from a Logit regressions estimated separately for each 5-year sub-period.

\footnotetext{
${ }^{20}$ Interestingly in the period 2008-2014, China would be an optimal trade partner for all of the European countries included in the estimation except for Bulgaria and Slovenia.

${ }^{21}$ In the lower panel we predict RTAs probabilities imposing a marginal reduction in Chinese GVC participation by winsorizing the top 10 percent of $\mathrm{GVC}_{i j, t-5}^{\text {Income }}$.
} 
Table 2 - RTAs predicted probabilities: Goodness-of-fit

\begin{tabular}{|c|c|c|c|c|c|c|c|c|c|}
\hline \multirow[t]{2}{*}{ Period } & \multicolumn{2}{|c|}{ "Observed RTAs } & \multicolumn{2}{|c|}{$\operatorname{Pr}>0.5$} & \multicolumn{5}{|c|}{ Pr $>$ Sensitivity/Specificity } \\
\hline & $\begin{array}{l}\text { Pairs } \\
\text { (1) }\end{array}$ & $\begin{array}{c}\text { Frequency } \\
\text { (2) }\end{array}$ & $\begin{array}{c}\% \text { TP } \\
\text { (3) }\end{array}$ & $\begin{array}{c}\% \mathrm{TN} \\
(4)\end{array}$ & $\begin{array}{c}\text { Cut Off } \\
\text { (5) }\end{array}$ & $\begin{array}{c}\% \text { TP } \\
(6)\end{array}$ & $\begin{array}{c}\% \mathrm{TN} \\
(7)\end{array}$ & $\begin{array}{c}\mathrm{FN}^{A / l} \\
(8)\end{array}$ & $\begin{array}{c}\mathrm{FPCHN} \\
(9)\end{array}$ \\
\hline 1995-2001 & 5241 & 5.9 & 52.8 & 91.7 & 6.1 & 88.6 & 81.5 & 141 & 17 \\
\hline 2002-2007 & 7241 & 9.6 & 56.7 & 91.3 & 9.5 & 87.1 & 80.6 & 131 & 15 \\
\hline 2008-2014 & 12278 & 13.9 & 60.0 & 91.8 & 12.5 & 84.5 & 78.2 & 268 & 42 \\
\hline $1995-2014$ & 24760 & 9.8 & 56.8 & 91.5 & 9.6 & 86.4 & 79.8 & 522 & 42 \\
\hline
\end{tabular}

Note: TN "True Negative", TP "True Positives", FN "False Negative" (i.e. prediction of PT A $=0$ while observed $P T A=1$ ). Probability Cutoff $\mathrm{Pr}>$ Sen/Spe is computed separately for each subperiod. $F N^{A l l}$ refers to the number of false negative country pairs in the corresponding time period; FPCHN refers to the number of countries that should ratify an RTA with China in the corresponding time period. Full Sample: $N=159$.

Figure 6 - Optimal cutoff for the Logit model

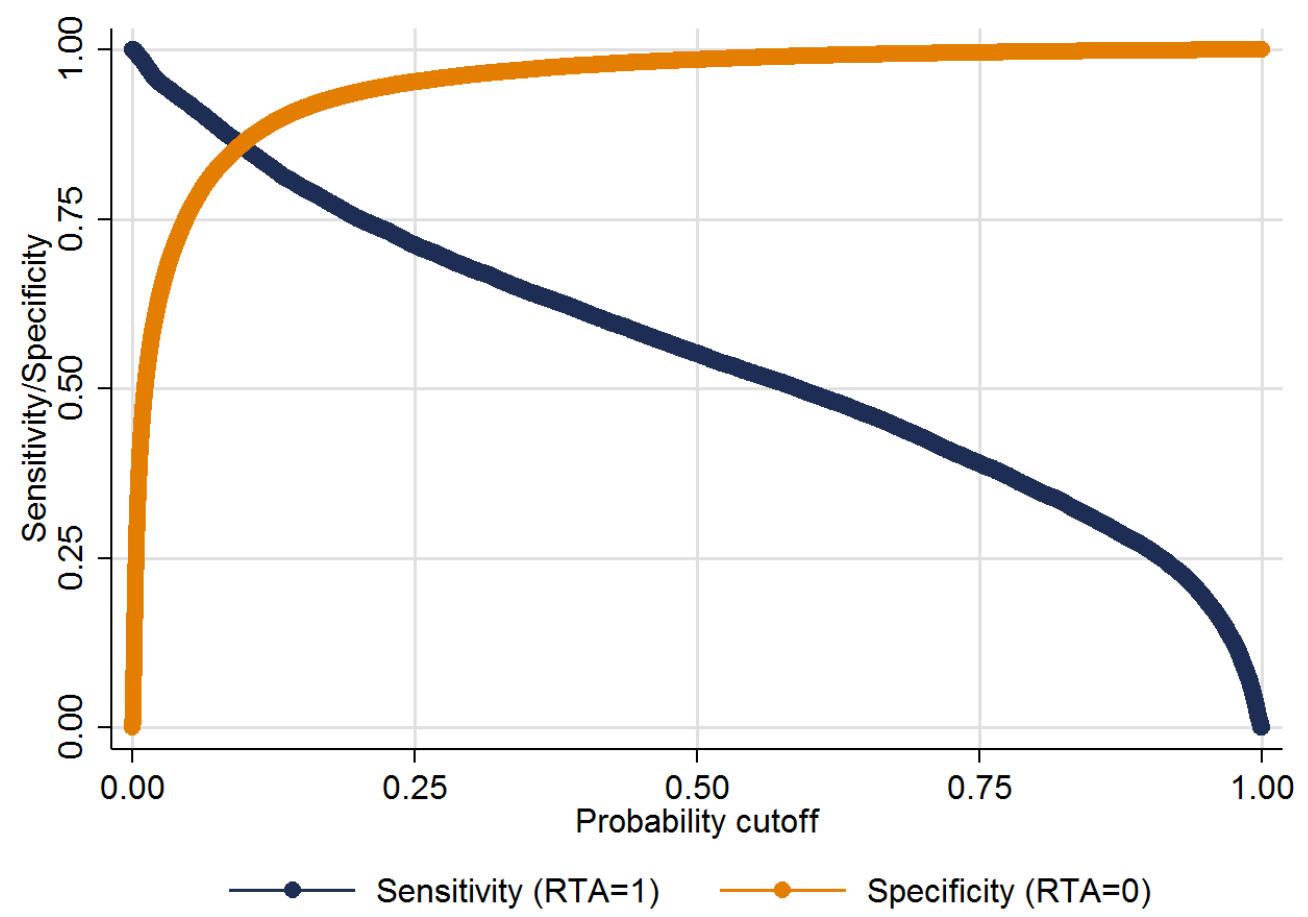

Note: PTAs Probabilities are obtained from a Logit regressions on the full sample period. 
Figure 7 - China: Optimal Trade Partners
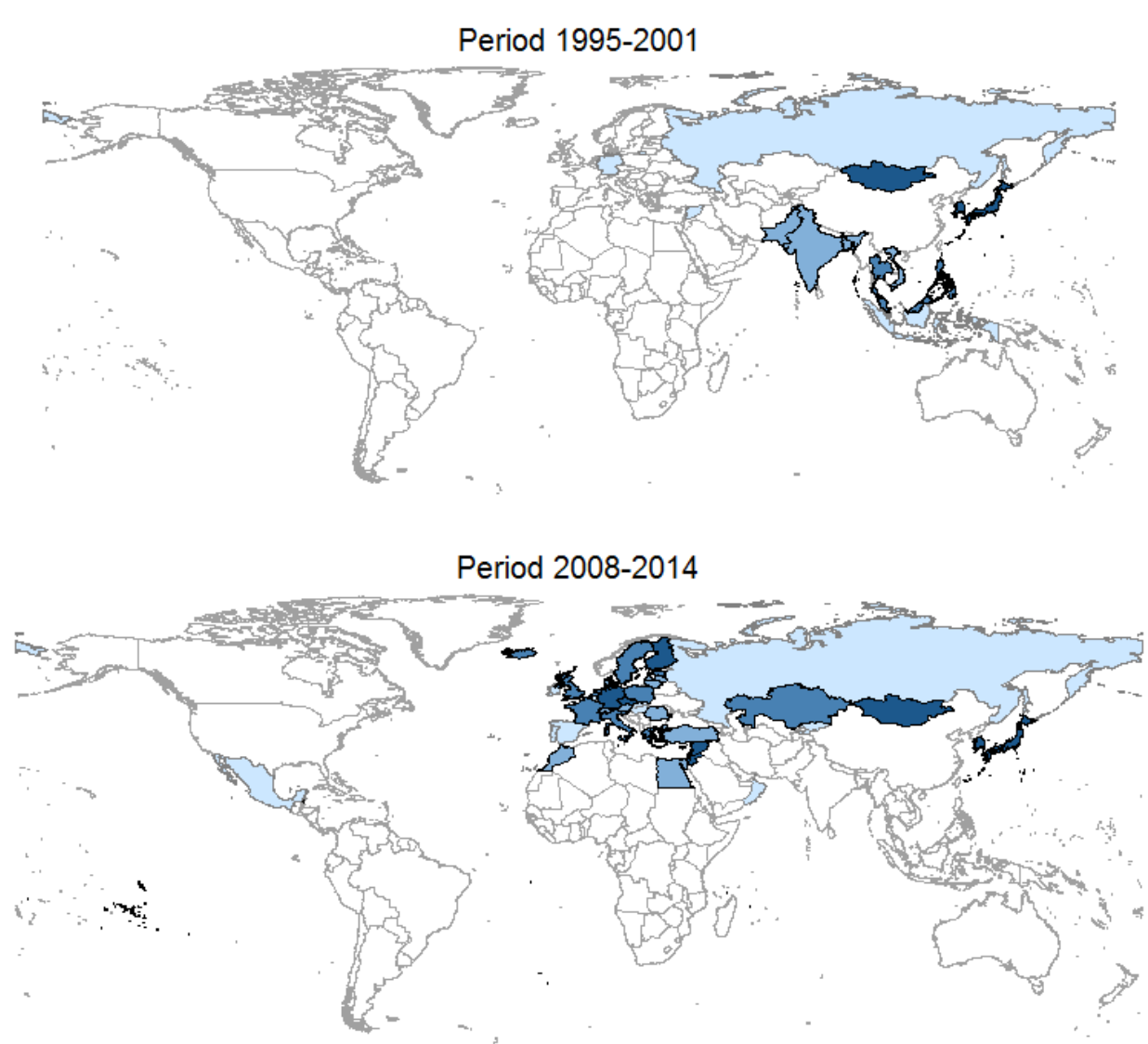

Note: Optimal RTAs for China, i.e. with a probability above the relevant threshold. The probability of signing an RTA is indicated by the nuances of blue: the darkest color, the highest probability of signing. 
Figure 8 - China: Optimal Trade Partners with and without GVCs income regressors
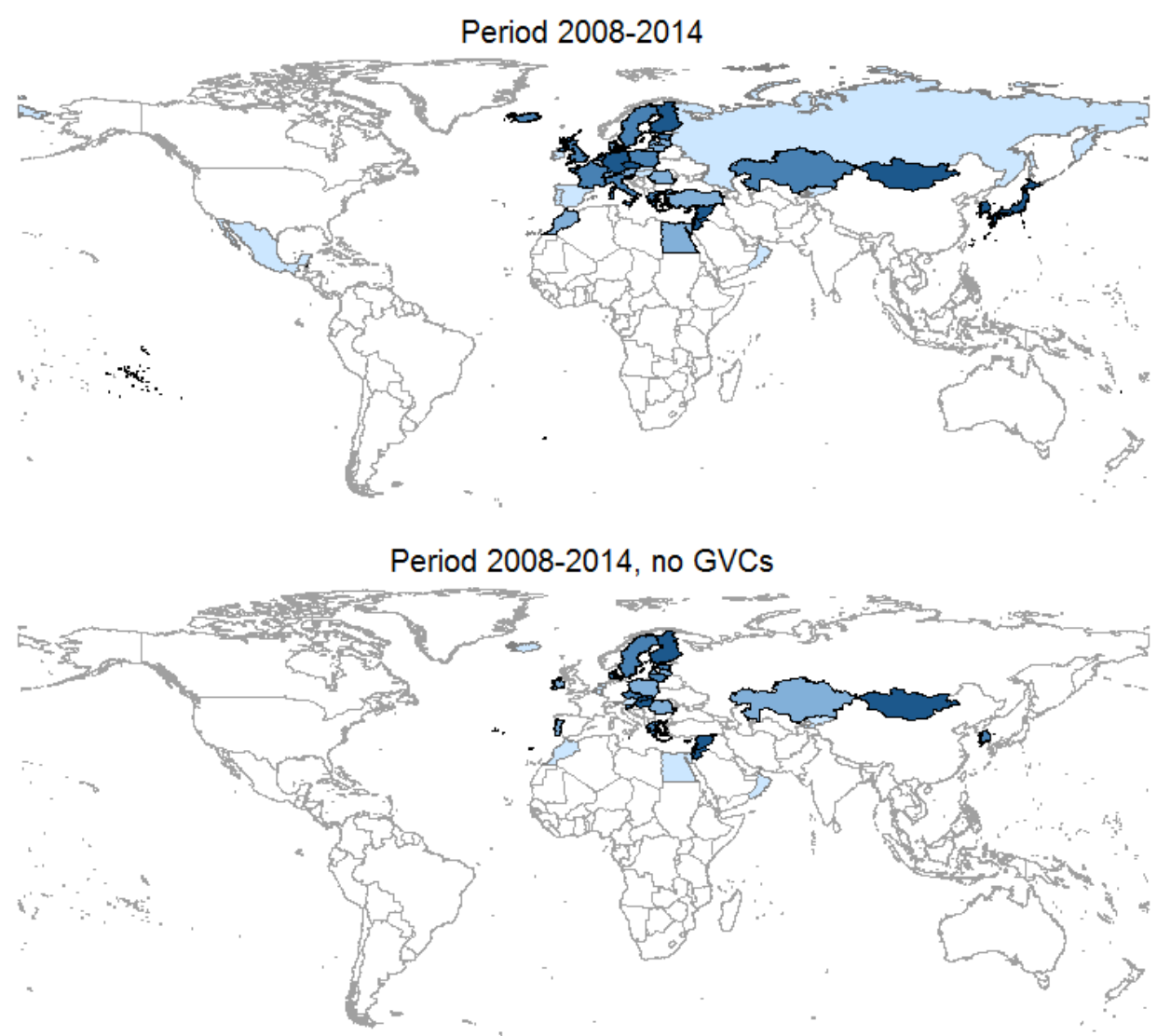

Note: Optimal RTAs for China, i.e. with a probability above the relevant threshold. In the lower panel we predict RTAs probabilities imposing a marginal reduction in Chinese GVC participation by winsorizing the top 10 percent of $\mathrm{GVC}_{i j, t-5}^{\text {Income }}$. The probability of signing an RTA is indicated by the nuances of blue: the darkest color, the highest probability of signing. 


\section{General Equilibrium Effects of an Alternative Geography of RTAs}

We are now fully equipped to quantify the trade and welfare impacts of a change in the overall structure of trade costs. What we need to do in this section is changing the vector of signed agreements (or not signed, recall that our indicator of RTA between $i$ and $j$ is dichotomic) for each country pair. We can decide to "sign" agreements that were wrongly predicted (the "false positive") or to withdraw $i$ and $j$ for agreements wrongly predicted as absent (the "false negative"). So doing we will held the set of correctly predicted positive and negative constant.

Importantly, third country effects, or more generally the so-called "general equilibrium effects" have to be taken on board. We know since Anderson and Van Wincoop (2003) that multilateral resistance terms (MRT thereafter) play a role here. These terms can be considered as general equilibrium trade cost indexes. The inward MRT will account for the impact on consumers at destination and the outward MRT the impact on producers in the origin country. As said above, signing a new RTA has a direct effect on $X_{i j}$ holding the MRT terms constant (this is the partial effect in the "classical" gravity literature), and an indirect effect through the change in the inward and outward MRTs (these are the conditional general equilibrium effects). Finally the effect on the price of the variety exported by the representative producer and on the expenditure in the exporting country are additional general equilibrium full endowment effects (Head and Mayer, 2014). To proceed, we need data on output and expenditure, because the right benchmark for trade integration is the domestic economy (Yotov, 2012).

\subsection{Welfare Impacts of an Alternative Geography of RTAs in a Structural Gravity System}

In our evaluation of the structural effects of RTAs we start from the usual structural gravity system.

The series of partial and general equilibrium effects referred to above can be specified more precisely with the usual gravity system described in equations (3-5). The direct and partial effect of a change in trade cost on bilateral trade between exporter $i$ and importer $j$ can be derived from equation (3), holding the MRTs constant. However the latter terms are not constant, because changing the trade costs between $i$ and $j$ is changing the overall structure of relative trade costs and prices 
between $i$ and $j$ and third countries. The indirect effect on $i$ and $j$ can accordingly be derived from equation (4). Would $i$ and $j$ enter into an RTA, this would lower the MRTs for these two countries but increase the MRTs for the rest of the world. Ultimately, the feedback on $i$ and $j$ of these changes in given by the conditional full-endowment general equilibrium effect described in terms of price of the representative firm and expenditure in $i$ (equation 5).

$$
\begin{aligned}
& \text { Partial Equilibrium }\left\{X_{i j}=\left(\frac{t_{i j}}{\Pi_{i} P_{j}}\right)^{1-\sigma} \frac{Y_{i} E_{j}}{Y}\right. \\
& \text { Conditional GE }\left\{\begin{array}{l}
\Pi_{i}^{1-\sigma}=\sum_{j}\left(\frac{t_{i j}}{P_{j}}\right)^{1-\sigma} \frac{E_{j}}{Y} \\
P_{j}^{1-\sigma}=\sum_{i}\left(\frac{t_{i j}}{\Pi_{i}}\right)^{1-\sigma} \frac{Y_{i}}{Y}
\end{array}\right. \\
& \text { Full Endowment GE }\left\{\begin{array}{l}
p_{i}=\frac{\left(Y_{i} / Y\right)^{\frac{1}{1-\sigma}}}{\alpha_{i} \Pi_{i}} \\
E_{i}==\phi_{i} Y_{i}=\phi_{i} Q_{i} p_{i}
\end{array}\right.
\end{aligned}
$$

Solving this non-linear system is complex and it was suggested by Feenstra (2015) to resort to an estimation of MRTs as country fixed effects. Silva and Tenreyro (2006) suggest relying on a PPML estimator fixing the issues of heteroscedasticity and zero trade flows. Finally, we know from Fally (2015) that such procedure authorizes to recover an exact approximation of the MRTs, up to a scalar. To avoid collinearity one fixed effect has to be dropped for a reference country. All other fixed effects will have to be expressed with respect to the one dropped (for the dropped country the MRT is one).

Using this framework we first define a baseline, corresponding to the actual set of RTAs and associated trade costs. This is the geography of RTAs as observed. Then, we shock this geography by "signing" the agreements predicted but not actually signed and "dismantling" the signed agreements that could not be predicted on economic grounds. To make the argument simpler, and because most of the untapped trade agreements involve China as a partner, we focus in the following on those FPs involving China. On the other hand, all FN are considered dismantled. This is our counterfactual. The last step is to compute the new general equilibrium indexes from which one 
derives the new welfare and thus welfare changes in deviation from the baseline for each country.

In order to proceed, we follow the procedure developed by (Yotov et al., 2017), which has four steps: a) solve the baseline gravity equation, b) define the counterfactual scenario, c) solve the counterfactual gravity model, d) build the relevant general equilibrium indexes.

First, we need an estimate for bilateral trade costs and the elasticity of trade to RTAs (step a). We start by estimating a structural gravity model, using PPML with 4-year intervals panel data, including both intra-national and international trade flows and covering the period 1990-2006. ${ }^{22}$ The estimated equation reads as follow:

$$
X_{i j, t}=\exp \left(R T A_{i j, t} \beta+\pi_{i, t}+\chi_{j, t}+\mu_{i j}\right)+\epsilon_{i j, t}
$$

Where $X_{i j, t}$ are the export flows from country $i$ to country $j . \pi_{i}$ and $\chi_{j}$ represents two set of exporter and importer fixed effects. Whereas $\mu_{i j}$ represents country-pair fixed effects capturing time invariant determinant of trade costs, such as: logarithm of distance, common border, common language and colonial ties. Finally, the variable $R T A_{i j, t}$ capture the presence of a regional trade agreement between country $i$ and $j$, the estimated parameter $\beta$ represents the associated average trade cost elasticity over the period considered. As noted in Yotov et al. (2017) there are three possible approaches to step a): estimation, calibration and a combination of the two named "estibration". ${ }^{23}$ In our application, we opt for the estimation procedure developed by Anderson et al. (2016) consisting of a General Equilibrium analysis with Poisson Pseudo Maximum Likelihood (GEPPML). Estimation results are reported in Table 3. ${ }^{24}$

\footnotetext{
${ }^{22}$ Data on intra and inter-national trade are from the CEPII TradeProd database. For documentation see de Sousa et al. (2012). We fill intra-national flows by linear interpolation between non-missing data whereas we extrapolate the remaining missing values using country total exports, following Baier et al. (2016).

${ }^{23}$ Examples of calibration methods are: the odd-ratio method, Head and Ries (2001); the tetrads method, Head et al. (2010); and the three countries method, Caliendo and Parro (2015). For the "estibration" method see Anderson et al. (2016).

${ }^{24}$ This procedure builds on the unique additive property of the PPML estimator (documented in Arvis and Shepherd (2013) and Fally (2015)) that ensures that the estimated importer and exporter fixed effects directly match with their the theoretical counterparts, $\exp \left(\widehat{\pi_{i, t}}\right)=\frac{Y_{i, t}}{\Pi_{i, t}^{1-\sigma}} \cdot E_{R, t}$. Where $\widehat{\pi_{i, t}}$ is the estimated exporter fixed effect, $\widehat{\Pi_{i, t}^{1-\sigma}}$ is the value of the inward multilateral resistance term and $E_{R, t}$ is the expenditure in the reference country. The same property holds for $\exp \left(\widehat{\chi_{i, t}}\right)$. Moreover, the estimation procedure based on PPML does not need to assume values for the CES shares, such as the preference parameter $\alpha_{i}$. See Anderson et al. (2016) for additional details.
} 
Equipped with the estimates from 6 it is possible to derive a matrix of bilateral trade costs for the baseline scenario (BLN):

$$
\widehat{t_{i j, t}^{1-\sigma}}=\exp \left(\widehat{\mu_{i j}}+R T A_{i j, t} \widehat{\beta}\right)
$$

The estimated $\widehat{t_{i j, t}^{1-\sigma}}$, combined with the gravity system $3-5$, yields the values for the key components of the general equilibrium analysis, such as consumer price index, inward and outward multilateral resistance terms (MRTs). ${ }^{25}$ The outward $(i)$ and inward $(j)$ multilateral resistance terms can be constructed as:

$$
\begin{aligned}
{\left[\widehat{\Pi_{i, t}^{1-\sigma}}\right] } & =\frac{Y_{i, t}}{\exp \left(\widehat{\pi_{i, t}}\right)} \cdot E_{R, t} \\
{\left[\widehat{P_{j, t}^{1-\sigma}}\right] } & =\frac{E_{j, t}}{\exp \left(\widehat{\chi_{j, t}}\right)} \cdot \frac{1}{E_{R, t}}
\end{aligned}
$$

Where, $Y_{i, t}$ represents the value of country $i$ domestic production whereas $E_{j, t}$ is the aggregate expenditure of country $j .{ }^{26}$ The sub-script $R$ refers to the reference country for the normalization, i.e. Germany.

We know turn to the definition of the counterfactual scenario (step $b$ ). We use the estimated probabilities from model 1 two derive two set of "endogenous" counterfactuals:

1. "False Positives ${ }^{C H N ": ~ R T A s ~ w i t h ~ C h i n a ~ t h a t ~ s h o u l d ~ b e ~ r a t i f i e d, ~ c o n s i d e r i n g ~ t h a t ~ t h e ~ p r e d i c t e d ~}$ probabilities are above the optimal threshold: $R T A_{i j, t}^{F P, C H N}$ thereafter.

2. "False Negatives": RTAs ratified even if the predicted probability was below the optimal threshold, RT $A_{i j, t}^{F N}$ thereafter.

\footnotetext{
${ }^{25}$ Note that although both the baseline and the counterfactual calculations are computed for individual cross-sections (1994, 2002 and 2006), the underlying values of $\widehat{\beta}$ and $\widehat{\mu_{i j}}$ are computed over the whole period and accordingly are time-invariant. As $3.2 \%$ of the estimated $\widehat{\mu_{i j}}$ are not identified, we replace missing missing trade costs with predictions from the standard gravity regression using the logarithm of distance, common border, common language and colonial ties as predictors.

${ }^{26}$ Note that since we include intra-national trade flows $Y_{i, t}=\sum_{j} X_{i j, t}$ and $E_{j, t}=\sum_{i} X_{i j, t}$
} 
We can know solve the counterfactual (CFL) gravity model by imposing the new vector of trade policies (step c).

Considering the "False Positives" ${ }^{C H N}$ counterfactual, the estimated equation becomes:

$$
X_{i j, t}=\exp \left(R T A_{i j, t}^{F P, C H N \bar{\beta}}+\pi_{i, t}^{C F L}+\chi_{j, t}^{C F L}+\overline{\mu_{i j}}\right)+\epsilon_{i j, t}
$$

where the coefficients $\bar{\beta}$ and $\overline{\mu_{i j}}$ have been constrained to the baseline values.

As for the baseline, estimates from Equation 7 deliver the counterfactual values for multilateral resistance terms, $\widehat{\pi_{i, t}^{C F L}}$ and $\widehat{\chi_{j, t}^{C F L}}$. Those estimates are the building blocks of the iterative procedure used to build the "Full Endowment" effect of the simulated trade policy $\left(R T A_{i j, t}^{F P, C H N}\right)$. "Full Endowment" general equilibrium effects include the adjustments of factory-gate prices (implied by the market clearing condition in Equation 5) and the endogenous values of income, expenditure and trade.

Changes in factory-gate prices between CFL and BLN are simply:

$$
\Delta p_{i, t}^{C F L}=\frac{p_{i, t}^{C F L}}{p_{i, t}}=\left(\frac{\exp \left(\widehat{\pi}_{i, t}^{C F L}\right) / E_{R, t}^{C F L}}{\exp \left(\widehat{\pi}_{i, t}\right) / E_{R, t}}\right)^{\frac{1}{1-\sigma}}
$$

Whereas the endogenous change in the value of income (or expenditure) in the CFL compared to BLN is defined as:

$$
Y_{i, t}^{C F L}=\frac{p_{i, t}^{C F L}}{p_{i, t}} \cdot Y_{i, t}
$$

The endogenous changes in the values of income and expenditure generates a further adjustment in MRTs that, in turn, is translated in a new matrix of bilateral trade flows, $X_{i j, t}^{C F L}$. Estimation of Equation 7 proceeds iteratively, with the endogenous bilateral trade flows $X_{i j, t}^{C F L}$, until the change in factory-gate prices is approximately zero. Once the iterative algorithm converges, the latest set of fixed effects is used to build the "Full Endowment" indexes (Ful/): factory-gate prices, MRTs, 
income, expenditure and trade.

Finally, it is now possible to quantify the general equilibrium effect of the simulated trade policy as the percentage difference between the baseline (BLN) and the (Full) counterfactual scenarios $($ step $d){ }^{27}$

For a given country, the baseline real GDP is defined as $R G D P^{B L N}=\frac{Y^{B L N}}{\left(I M R^{B L N}\right)^{\frac{1}{1-\sigma}}}$. Where $I M R^{B L N}$ is the Inward MRT in the baseline, whereas the "Full Endowment" real GDP is derived in the same fashion. The elasticity of substitution among varieties from different countries plays a crucial role in the estimation of factory-gate prices as well as for welfare aggregates, in the empirical results presented below we adopt the conservative value $\sigma=5$.

For the counterfactual defined as "False Negatives", and corresponding to RTAs ratified while the predicted probability was below the threshold, we proceed exactly with the same sequence.

Table 3 - PPML: Gravity Estimations of RTA direct effect

\begin{tabular}{lccc|cc}
\hline $\begin{array}{l}\text { Dep Var: } \\
\mathrm{X}_{\text {ijt }}\end{array}$ & $(1)$ & $(2)$ & $(3)$ & $\begin{array}{c}1990-2002 \\
(4)\end{array}$ & $\begin{array}{c}1994-2006 \\
(5)\end{array}$ \\
\hline PTA & $0.448^{* * *}$ & $0.454^{* * *}$ & $0.448^{* * *}$ & $0.649 * * *$ & $0.185^{* *}$ \\
& $(0.107)$ & $(0.110)$ & $(0.112)$ & $(0.093)$ & $(0.088)$ \\
& & & & & \\
\hline N Cty & 111 & 67 & $67+\mathrm{ROW}$ & 111 & 111 \\
Observations & 15364 & 14872 & 14884 & 45952 & 46720 \\
FEs & it, jt, ij & it, jt, ij & it, jt, ij & it, jt, ij & it, jt, ij \\
\hline \hline
\end{tabular}

Exporter-time (it), Importer-time $(j t)$ and Exporter-Importer $(i j)$ fixed effects are always included. Standard errors in parenthesis are clustered by country-pair, $* * * p<0.01, * * p<0.05, * p<0.1$. ROW is the rest of the world aggregate.

\subsection{Welfare changes in numbers}

In this section we report the results of the general equilibrium gravity estimates. ${ }^{28}$ We are interested in the (weighted) average effect on export and real GDP of our two counterfactual exercises, FN ${ }^{A l l}$ and FPCHN.

${ }^{27}$ Using notation $\widehat{\overparen{N D}}$ for our variables of interest, i.e. either exports or real GDP, it is simply computed as:

$$
\Delta \widehat{I N D}_{i} \%=\frac{\widehat{I N D}_{i}^{\text {Full }}-\widehat{I N D}_{i}^{B L N}}{\widehat{I N D}_{i}^{B L N}} \times 100
$$

\footnotetext{
${ }^{28}$ We assume an elasticity of substitution equal to $\sigma=5$ as referred above. In the Annex we also present the results assuming $\sigma=7$.
} 
The estimated effects of removing the non-optimal bilateral RTAs ratified in the corresponding period $\left(F N^{A / l}\right)$ are given in the first two columns of Table 4 and their distribution is reported in Figure 9. ${ }^{29}$ On one hand, for the countries directed involved (i.e. Treated, in column 2), removing those agreements would cause a loss of aggregate exports in the range of 0.30 and $0.87 \%$ and a negligible reduction in real GDP (between 0.03 and $0.06 \%$ ). There is indeed an issue related to the bilateral nature of our variable of RTAs: EU countries enter jointly in any new agreement. We adopt here the rule of thumb of majority by sake of simplicity and further consider in column 3 that false negative against the majority of EU members will be false negatives with the remaining members as well; the overall pictures is hardly affected. On the other hand, the expected gain for the rest of the world (i.e. Untreated in column 1), is even smaller. This first series of result is suggesting that false negative RTAs, originally at odds with the underlying economic determinants, did not divert significantly world trade flows once in place, and created instead conditions for (moderate) further trade expansion between participating countries.

Conversely, Column 4 and 5 of Table 4 report the expected gains from a deeper integration with China, in line with the geography of RTAs predicted by economic determinants. Their distribution is reported in Figure 10. Mechanisms at stake, justifying this additional set of RTAs, refer to the shift of the gravity center of the world economy towards factory China and the associated involvement of China in GVCs going beyond surrounding countries (this was indeed suggested by the maps previously shown - see Figure 7). Not surprisingly, given the size of the economies involved, the estimated effects are now significantly higher. For the treated countries, signing an RTA with China is expected to increase exports between 4.56 and $5.49 \%$ while the increase in real GDP is evaluated between 0.41 and $0.49 \%$. This would come at no cost for the untreated countries: the estimated impact is about one order of magnitude smaller and approximately zero.

The currently negotiated RTA involving China, the member states of the Association of Southeast Asian Nations (ASEAN-10) and the other countries with which ASEAN has RTAs in force (namely Australia, India, Japan, South Korea and New Zealand) can also be used as a counterfactual. The so-called Regional Comprehensive Economic Partnership (RCEP) would have had economic

\footnotetext{
${ }^{29}$ Note that the distribution of individual effects includes both Treated and Untreated countries.
} 
impacts shown in table 5 for three sub-periods. Interestingly, the impact on Chinese exports is much smaller in 2008-14 compared to 1995-01 or even 2002-07. This also translates into Chinese welfare gains divided by 4 if one compares 2008-14 with 1995-01. This reduced benefit of signing this agreement is mirroring the fact that China is becoming a global actor. For other countries of RCEP, the agreement has also lost interest but mainly over the period 2008-14. This agreement would come a t a cost for third countries, but less so in the recent period for symmetric reasons. Our take on this counterfactual is that the RCEP was an agreement worth signing before the negotiations started (in November 2012). It is progressively becoming less relevant as the main economic actor in the region is increasing global.

\section{Figure 9 - Distribution of GE Effects: False Negatives}
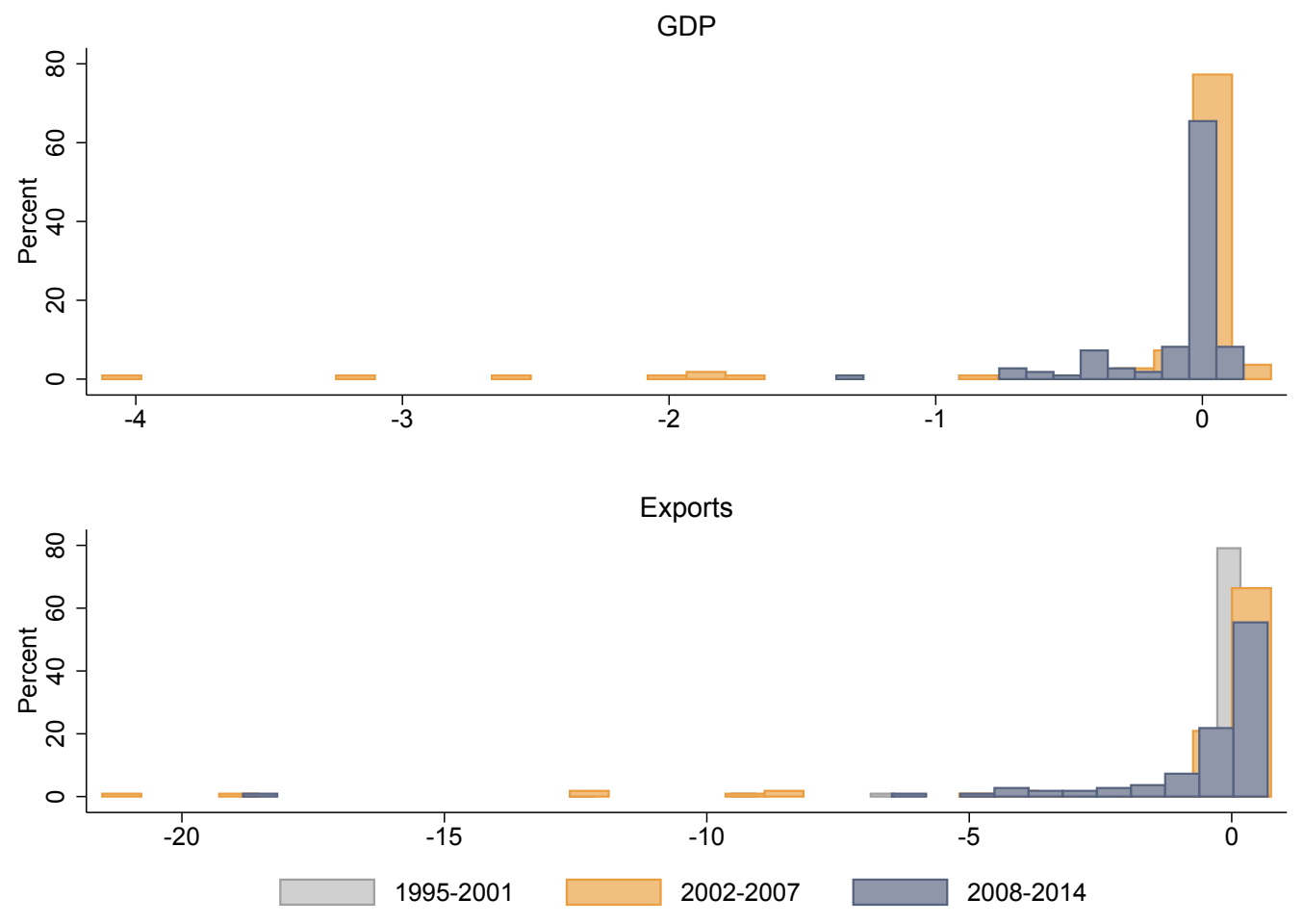

Note: expected cost of removing non optimal RTAs. 
Figure 10 - Distribution of GE Effects: False Positives ${ }^{C H N}$
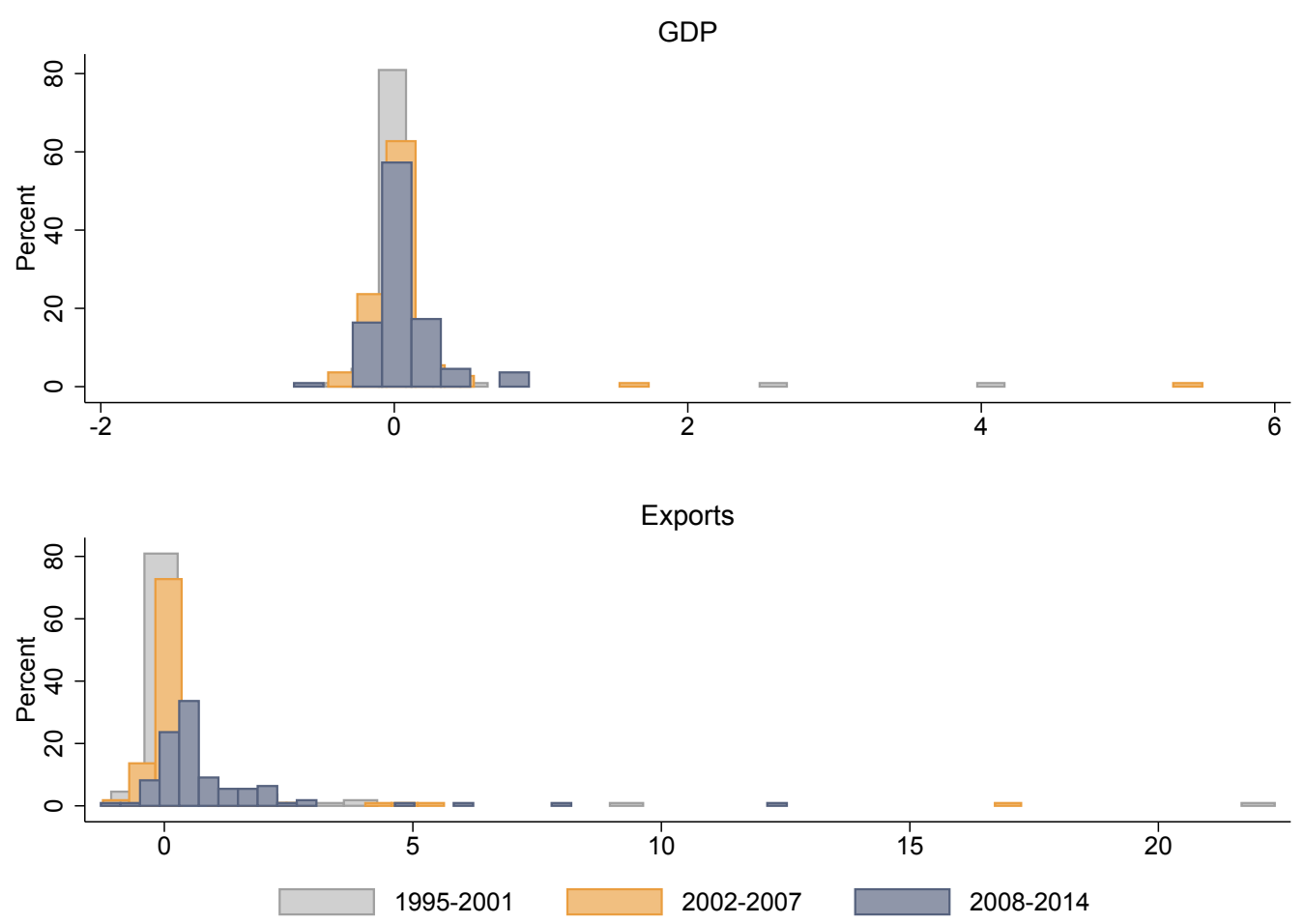

Note: potential gains from ratifying an RTA with China.

Table 4 - Weighted Average General Equilibrium effects of RTAs shock $(\sigma=5)$

\begin{tabular}{lccc|cc}
\hline & \multicolumn{3}{c|}{ False Negatives, FN } & \multicolumn{2}{c}{ Fall } \\
& $\begin{array}{c}\text { Untreated } \\
(1)\end{array}$ & $\begin{array}{c}\text { Treated } \\
(2)\end{array}$ & $\begin{array}{c}\text { Treated EU } \\
(3)\end{array}$ & $\begin{array}{c}\text { Untreated } \\
(4)\end{array}$ & $\begin{array}{c}\text { Treated } \\
(5)\end{array}$ \\
\hline & & & & & \\
$\Delta$ Export $_{1994}^{95-01}$ & 0.037 & -0.320 & -0.321 & -0.136 & 4.560 \\
$\Delta$ Export $_{2002}^{02-07}$ & 0.277 & -0.702 & -0.702 & -0.125 & 5.253 \\
$\Delta$ Export $_{2006}^{08-14}$ & 0.198 & -0.877 & -0.881 & 0.070 & 5.496 \\
\hline GDP $_{195-01}^{954}$ & 0.002 & -0.031 & -0.031 & -0.024 & 0.411 \\
$\Delta$ GDP $_{2002}^{02-07}$ & 0.062 & -0.065 & -0.065 & -0.037 & 0.524 \\
$\Delta$ GDP $_{2006}^{08-14}$ & 0.028 & -0.058 & -0.059 & -0.057 & 0.495 \\
\hline \hline
\end{tabular}

Results from separate cross-sectional regressions: subscript indicates the year of the observed trade flow, superscript the period of RTA shocks. Baseline Real GDPs are used as weights. 
Table 5 - Weighted Average General Equilibrium effects of RCEP $(\sigma=5)$

\begin{tabular}{lc|cc}
\hline & & \multicolumn{2}{c}{ RCEP Agreement } \\
& $\begin{array}{c}\text { Untreated } \\
(1)\end{array}$ & $\begin{array}{c}\text { Treated } \\
(2)\end{array}$ & $\begin{array}{c}\text { China } \\
(3)\end{array}$ \\
\hline & & & \\
$\Delta$ Export $_{1994}$ & -0.563 & 13.627 & 15.975 \\
$\Delta$ Export $_{2002}$ & -0.503 & 13.232 & 11.936 \\
$\Delta$ Export $_{2006}$ & -0.324 & 8.265 & 6.136 \\
\hline M $_{\Delta \text { GDP }_{1994}}$ & -0.037 & 1.038 & 1.696 \\
$\Delta$ GDP $_{2002}$ & -0.035 & 1.286 & 1.074 \\
$\Delta$ GDP $_{2006}$ & -0.027 & 0.879 & 0.421 \\
\hline \hline
\end{tabular}

Results from separate cross-sectional regressions: subscript indicates the year of the observed trade flow, superscript the period of RTA shocks. Baseline Real GDPs are used as weights. RCEP: Regional Comprehensive Economic Partnership. RCEP countries in the estimation sample: Australia, China, Indonesia, India, Japan, Cambodia, Korea, Malaysia, New-Zealand, Philippines, Singapore, Thailand, Vietnam. 


\section{Conclusion}

Economic determinants, here extended to the involvement of country-pairs in the fragmentation of value chains, help predicting the geography of regional trade agreements. The actual set of agreements does not perfectly fit the prediction however. Certain country pairs did not embark in potentially fruitful agreements, whereas some pairs did but at odds with what economic determinants would have suggested. This contrasted evidence is suggesting that a counterfactual situation where the geography of RTAs is redesigned along the lines of our predictions is worth investigating. Using a structural gravity general equilibrium framework, we evaluated such counterfactual, focusing on the abandon of "non-economic RTAS" and the implementation of those agreements to be signed by China. Two main results are worth mentioning. First, non-economic RTAs become endogenously more desirable, on average, as country-pairs involved in increasingly trade together. Removing these agreements would lead to a loss for the involved countries, without bringing benefits to third-countries. Second, China has become a large super-trader deeply involved in GVCs beyond the boundaries of its region: gains to signing the corresponding predicted agreements is a low-hanging fruit, whereas the economic gains to be reaped from the RCEP - a regional initiative - are progressively vanishing. 


\section{Bibliography}

Amador, J. and Cabral, S. (2017), 'Networks of value-added trade', The World Economy 40(7), 1291-1313.

Anderson, J. E. and Van Wincoop, E. (2003), 'Gravity with gravitas: a solution to the border puzzle', the american economic review 93(1), 170-192.

Anderson, J. E. and Yotov, Y. V. (2010), 'The changing incidence of geography', The American Economic Review 100(5), 2157-2186.

URL: http://www.jstor.org/stable/41038758

Anderson, J., Larch, M. and Yotov, Y. (2016), Estimating General Equilibrium Trade Policy Effects: GE PPML, School of Economics Working Paper Series 2016-6, LeBow College of Business, Drexel University.

Arkolakis, C., Ramondo, N., Rodriguez-Clare, A. and Yeaple, S. (2013), Innovation and Production in the Global Economy, NBER Working Papers 18972, National Bureau of Economic Research, Inc.

URL: https://ideas.repec.org/p/nbr/nberwo/18972.htm/

Arvis, J.-F. and Shepherd, B. (2013), 'The Poisson quasi-maximum likelihood estimator: a solution to the Śadding upŠ problem in gravity models', Applied Economics Letters 20(6), 515-519.

URL: https://ideas.repec.org/a/taf/apeclt/v20y2013i6p515-519.htm/

Baier, S. L. and Bergstrand, J. H. (2004), 'Economic determinants of free trade agreements', Journal of International Economics 64(1), 29-63.

URL: https://ideas.repec.org/a/eee/inecon/v64y2004i1p29-63.htm/

Baier, S. L. and Bergstrand, J. H. (2007), 'Do free trade agreements actually increase members' international trade?', Journal of international Economics 71(1), 72-95.

Baier, S. L., Bergstrand, J. H. and Mariutto, R. (2014), 'Economic Determinants of Free Trade Agreements Revisited: Distinguishing Sources of Interdependence', Review of International Economics 22(1), 31-58.

URL: https://ideas.repec.org/a/bla/reviec/v22y2014i1p31-58.htm/

Baier, S. L., Yotov, Y. V. and Zylkin, T. (2016), On the Widely Differing Effects of Free Trade Agreements: Lessons from Twenty Years of Trade Integration, CESifo Working Paper Series 6174, CESifo Group Munich.

Behrens, K., Mion, G., Murata, Y. and Südekum, J. (2014), 'Trade, wages, and productivity', International Economic Review 55(4), 1305-1348.

Caliendo, L., Feenstra, R. C., Romalis, J. and Taylor, A. M. (2015), Tariff Reductions, Entry, and Welfare: Theory and Evidence for the Last Two Decades, NBER Working Papers 21768, National Bureau of Economic Research, Inc.

URL: https://ideas.repec.org/p/nbr/nberwo/21768.htm/

Caliendo, L. and Parro, F. (2015), 'Estimates of the Trade and Welfare Effects of NAFTA', Review 
of Economic Studies 82(1), 1-44.

URL: https://ideas.repec.org/a/oup/restud/v82y2015i1p1-44.htm/

Costinot, A., Donaldson, D. and Komunjer, I. (2012), 'What Goods Do Countries Trade? A Quantitative Exploration of Ricardo's Ideas', Review of Economic Studies 79(2), 581-608.

URL: https://ideas.repec.org/a/oup/restud/v79y2012i2p581-608.htm/

de Sousa, J., Mayer, T. and Zignago, S. (2012), 'Market access in global and regional trade', Regional Science and Urban Economics 42(6), 1037-1052.

Disdier, A.-C. and Head, K. (2008), 'The puzzling persistence of the distance effect on bilateral trade', The Review of Economics and statistics 90(1), 37-48.

Eaton, J., Kortum, S. S. and Sotelo, S. (2012), International Trade: Linking Micro and Macro, NBER Working Papers 17864, National Bureau of Economic Research, Inc.

URL: https://ideas.repec.org/p/nbr/nberwo/17864.htm/

Egger, H., Egger, P. and Greenaway, D. (2008), 'The trade structure effects of endogenous regional trade agreements', Journal of international Economics 74(2), 278-298.

Egger, P. and Larch, M. (2008), 'Interdependent preferential trade agreement memberships: An empirical analysis', Journal of International Economics 76(2), 384-399.

Egger, P. and Larch, M. (2011), 'An assessment of the Europe agreements' effects on bilateral trade, GDP, and welfare', European Economic Review 55(2), 263-279.

URL: https://ideas.repec.org/a/eee/eecrev/v55y2011i2p263-279.htm/

Egger, P., Larch, M., Staub, K. E. and Winkelmann, R. (2011), 'The Trade Effects of Endogenous Preferential Trade Agreements', American Economic Journal: Economic Policy 3(3), 113-43.

Fally, T. (2015), 'Structural gravity and fixed effects', Journal of International Economics 97(1), 76 $-85$.

URL: http://www.sciencedirect.com/science/article/pii/S0022199615001026

Feenstra, R. C. (2015), Advanced international trade: theory and evidence, Princeton university press.

Feenstra, R. C., Inklaar, R. and Timmer, M. P. (2015), 'The Next Generation of the Penn World Table', American Economic Review 105(10), 3150-82.

Head, K. and Mayer, T. (2014), Gravity Equations: Workhorse, Toolkit, and Cookbook, Vol. 4 of Handbook of International Economics, Elsevier, chapter 0, pp. 131-195.

Head, K., Mayer, T. and Ries, J. (2010), 'The erosion of colonial trade linkages after independence', Journal of International Economics 81(1), 1 - 14.

URL: http://www.sciencedirect.com/science/article/pii/S0022199610000036

Head, K. and Ries, J. (2001), 'Increasing returns versus national product differentiation as an explanation for the pattern of u.s.-canada trade', The American Economic Review 91(4), 858876.

URL: http://www.jstor.org/stable/2677816 
Heid, B. and Larch, M. (2016), 'Gravity with unemployment', Journal of International Economics 101(C), 70-85.

URL: https://ideas.repec.org/a/eee/inecon/v101y2016icp70-85.htm/

Helpman, E. (1987), 'Imperfect competition and international trade: evidence from fourteen industrial countries', Journal of the Japanese and international economies 1(1), 62-81.

Johnson, R. C. (2017), Measuring Global Value Chains, NBER Working Papers 24027, National Bureau of Economic Research, Inc.

URL: https://ideas.repec.org/p/nbr/nberwo/24027.htm/

Johnson, R. C. and Noguera, G. (2012a), 'Accounting for intermediates: Production sharing and trade in value added', Journal of international Economics 86(2), 224-236.

Johnson, R. C. and Noguera, G. (2012b), 'Proximity and production fragmentation', American Economic Review 102(3), 407-11.

Krugman, P. (1991), 'The move toward free trade zones', Economic Review-Federal Reserve Bank of Kansas City 76(6), 5.

Lenzen, M., Kanemoto, K., Moran, D. and Geschke, A. (2012), 'Mapping the structure of the world economy', Environmental Science \& Technology 46(15), 8374-8381. PMID: 22794089.

URL: https://doi.org/10.1021/es300171x

Lenzen, M., Moran, D., Kanemoto, K. and Geschke, A. (2013), 'Building eora: A global multiregion inputâĂŞoutput database at high country and sector resolution', Economic Systems Research 25(1), 20-49.

URL: https://doi.org/10.1080/09535314.2013.769938

Los, B., Timmer, M. P. and Vries, G. J. (2015), 'How global are global value chains? a new approach to measure international fragmentation', Journal of Regional Science 55(1), 66-92.

Marshall, M. G., Ted Robert, G. and Jaggers, K. (2016), Polity IV Project: Dataset Users' Manual, Technical report, Center for Systemic Peace.

URL: www.systemicpeace.org/polity

Mayer, T., Vicard, V. and Zignago, S. (2018), The cost of non-europe, revisited, Technical report, CEPR Discussion Paper.

Mayer, T. and Zignago, S. (2011), Notes on CEPll's distances measures: The GeoDist database, Working Papers 2011-25, CEPII research center.

URL: https://ideas.repec.org/p/cii/cepidt/2011-25.htm/

Silva, J. S. and Tenreyro, S. (2006), 'The log of gravity', The Review of Economics and statistics 88(4), 641-658.

Timmer, M. P., Los, B., Stehrer, R. and Vries, G. J. (2013), 'Fragmentation, incomes and jobs: an analysis of European competitiveness', Economic Policy 28(76), 613-661.

URL: https://ideas.repec.org/a/bla/ecpoli/v28y2013i76p613-661.html

Vicard, V. (2011), 'Determinants of successful regional trade agreements', Economics Letters 
111(3), 188-190.

Wooldridge, J. M. (2010), Econometric Analysis of Cross Section and Panel Data, Vol. 1 of MIT Press Books, The MIT Press.

Yotov, Y., Piermartini, R., J.-A., M. and Larch, M. (2017), An Advanced Guide to Trade Policy Analysis: The Structural Gravity Model, United Nations publication, World Trade Organization. URL: https://books.google.fr/books?id=cWX5MAAACAAJ

Yotov, Y. V. (2012), 'A simple solution to the distance puzzle in international trade', Economics Letters 117(3), 794-798. 


\section{Appendix}

\subsection{Variable construction \& Data Sources}

Real GDP and population is from Penn World Tables 9.0 (for more details see Feenstra et al., 2015), great circle distance between countries are from CEPII (see Mayer and Zignago, 2011), multiregion input-output tables are from the EORA mrio database. The economic variable included in the estimation of 1 are computed as follow:

$$
\begin{aligned}
& \quad \text { Natural }_{i j} \quad=\log \left(\frac{1}{\text { dist }_{i j}}\right) \\
& \text { Remote }_{i j} \quad=0.5\left\{\log \left[\sum_{k \neq j} D_{i s t} / n-1\right]+\log \left[\sum_{k \neq i} \operatorname{Dist}_{j k} / n-1\right]\right\} \\
& G D P_{i j t}^{\text {sum }} \quad=\log \left(g d p_{i t}+g d p_{j t}\right) \\
& G D P_{i j t}^{\operatorname{sim}} \quad=\log \left(1-\left[g d p_{i t} /\left(g d p_{i t}+g d p_{j t}\right)\right]^{2}-\left[g d p_{j t} /\left(g d p_{i t}+g d p_{j t}\right)\right]^{2}\right) \\
& D K L_{i j t} \quad=\left|\log \left(g d p_{i t} / p o p_{i t}\right)-\log \left(g d p_{i t} / p o p_{i t}\right)\right| \\
& D R O W K L_{i j t} \quad=0.5\left\{\left|\log \left(\sum_{k t \neq i t} g d p_{k t} / \sum_{k t \neq i t} p o p_{k t}\right)-\log \left(g d p_{i t} / p o p_{i t}\right)\right|+\right. \\
& \left.\left|\log \left(\sum_{k t \neq j t} g d p_{k t} / \sum_{k t \neq j t} p o p_{k t}\right)-\log \left(g d p_{j t} / p o p_{j t}\right)\right|\right\} \\
& \text { MRTA } A_{i t} \quad=\sum_{k \neq j}^{N} R T A_{i k t} \\
& \operatorname{MRTA}_{j t} \quad=\sum_{k \neq i}^{N} R T A_{i k t} \\
& \text { ROWRTA } A_{i j t} \quad=\sum_{k \neq i}^{N} \sum_{l \neq j}^{N} R T A_{l k t} \\
& G \vee C_{i j t}^{i n c o m e} \quad=\log \left(G V C_{i j t}^{i->j}+G V C_{i j t}^{j->i}\right)
\end{aligned}
$$




\subsection{Analysis of the residuals from the Logit regression}

In order to shed light on the role of political determinants in shaping RTA's predicted probability, we regress the residuals of Equation 1 on a series of political variables ${ }^{30}$. Namely, the cumulated number of Days of Conflict and the maximum level of Hostility over the period 1993-2001 (source: Correlates of War ${ }^{31}$; a measure of institutional quality by country and year (PolitylV ${ }^{32}$ ); a series of bilateral historical and political factors such as: common language, common religion, colonial ties, common legal origin Pre and Post transition plus a series of dummies for the legal system (i.e. fr, gr, sc, so, uk $)^{33}$.

Table ST1 reports the estimated coefficients confirming that political determinants strongly correlates with the residuals of the logistic regression from which we recover the predicted probabilities of RTAs.

\footnotetext{
${ }^{30}$ Residuals are computed as deviance residuals, measuring the disagreement between the maxima of the observed and the fitted log likelihood functions of Equation 1.

${ }^{31}$ Dyadic Militarized Interstate Dispute Data, Version 3.10, https : //correlatesofwar .org

${ }^{32}$ See Marshall et al. (2016).

${ }^{33}$ Source: Head et al. (2010).
} 
Table ST1 - Correlations of Logit residuals and political variables

\begin{tabular}{|c|c|c|c|c|c|c|c|}
\hline $\begin{array}{l}\text { Dep Var: } \\
\mid \text { Residualsijt } \mid\end{array}$ & $(1)$ & $(2)$ & (3) & (4) & (5) & (6) & $(7)$ \\
\hline Days of Conflict $(\log )_{i j}^{\text {sum }}$ & & $\begin{array}{c}0.059 * * * \\
(0.004)\end{array}$ & $\begin{array}{c}0.059 * * * \\
(0.004)\end{array}$ & $\begin{array}{c}0.046^{* * *} \\
(0.004)\end{array}$ & $\begin{array}{c}0.047 * * * \\
(0.004)\end{array}$ & $\begin{array}{c}0.041 * * * \\
(0.004)\end{array}$ & $\begin{array}{c}-0.018^{* *} \\
(0.009)\end{array}$ \\
\hline Hostility Level $\lim _{i j}$ & & $\begin{array}{c}0.077 * * * \\
(0.006)\end{array}$ & $\begin{array}{c}0.076 * * * \\
(0.006)\end{array}$ & $\begin{array}{c}0.068 * * * \\
(0.006)\end{array}$ & $\begin{array}{c}0.060 * * * \\
(0.006)\end{array}$ & $\begin{array}{c}0.073 * * * \\
(0.006)\end{array}$ & $\begin{array}{c}-0.035^{* * *} \\
(0.013)\end{array}$ \\
\hline Polity IV $i t$ & & & $\begin{array}{c}0.000 \\
(0.000)\end{array}$ & $\begin{array}{c}0.001^{* * *} \\
(0.000)\end{array}$ & $\begin{array}{c}0.001^{* * *} \\
(0.000)\end{array}$ & $\begin{array}{c}0.002 * * * \\
(0.000)\end{array}$ & $\begin{array}{c}-0.036 * * * \\
(0.001)\end{array}$ \\
\hline Polity IV $\mathrm{V}_{j t}$ & & & $\begin{array}{c}0.001^{* * *} \\
(0.000)\end{array}$ & $\begin{array}{c}0.001^{* * *} \\
(0.000)\end{array}$ & $\begin{array}{c}0.001^{* * *} \\
(0.000)\end{array}$ & $\begin{array}{c}0.002^{* * *} \\
(0.000)\end{array}$ & $\begin{array}{c}-0.025^{* * *} \\
(0.001)\end{array}$ \\
\hline Common Religion $_{i j}$ & & & & $\begin{array}{c}0.171^{* * *} \\
(0.005)\end{array}$ & $\begin{array}{c}0.165^{* * *} \\
(0.005)\end{array}$ & $\begin{array}{c}0.088 * * * \\
(0.003)\end{array}$ & $\begin{array}{c}-0.143^{* * *} \\
(0.019)\end{array}$ \\
\hline Colonial Ties $_{i j}$ & & & & $\begin{array}{c}0.193 * * * \\
(0.012)\end{array}$ & $\begin{array}{c}0.195^{* * *} \\
(0.012)\end{array}$ & $\begin{array}{c}0.172 * * * \\
(0.009)\end{array}$ & $\begin{array}{l}0.056^{* *} \\
(0.024)\end{array}$ \\
\hline Common Language $_{i j}$ & & & & $\begin{array}{c}0.200 * * * \\
(0.005)\end{array}$ & $\begin{array}{c}0.192 * * * \\
(0.005)\end{array}$ & $\begin{array}{c}0.084 * * * \\
(0.003)\end{array}$ & $\begin{array}{c}-0.113^{* * *} \\
(0.016)\end{array}$ \\
\hline Sibling Countries $_{i j}$ & & & & $\begin{array}{c}0.175^{* * *} \\
(0.005)\end{array}$ & $\begin{array}{c}0.176 * * * \\
(0.005)\end{array}$ & $\begin{array}{c}0.086 * * * \\
(0.003)\end{array}$ & $\begin{array}{c}0.212^{* * * *} \\
(0.016)\end{array}$ \\
\hline Common Legal Origins ${ }_{i j}^{P r e}$ & & & & & $\begin{array}{c}0.146^{* * *} \\
(0.004)\end{array}$ & $\begin{array}{c}0.087^{* * *} \\
(0.003)\end{array}$ & $\begin{array}{c}0.045^{* * *} * \\
(0.016)\end{array}$ \\
\hline Common Legal Origins ${ }_{i j}^{\text {Post }}$ & & & & & $\begin{array}{c}-0.158^{* * *} \\
(0.004)\end{array}$ & $\begin{array}{c}-0.073 * * * \\
(0.003)\end{array}$ & $\begin{array}{c}-0.125^{* * *} \\
(0.015)\end{array}$ \\
\hline Legal Origins $s_{i}^{\text {Dummies }}$ & Yes & Yes & Yes & Yes & Yes & Yes & Yes \\
\hline $\begin{array}{l}\text { Legal Origins }{ }_{j}^{\text {Dummies }} \\
\text { Sample }\end{array}$ & Yes & Yes & Yes & Yes & Yes & $\begin{array}{c}\text { Yes } \\
\operatorname{Res}_{i j t}<0\end{array}$ & $\begin{array}{c}\text { Yes } \\
\operatorname{Res}_{i j t}>0\end{array}$ \\
\hline Observations & 198,969 & 198,969 & 198,969 & 198,969 & 198,969 & 178,204 & 20,765 \\
\hline$R^{2}$ & 0.360 & 0.371 & 0.371 & 0.416 & 0.423 & 0.533 & 0.768 \\
\hline
\end{tabular}

Standard errors in parenthesis are robust to heteroscedasticity, $* * * p<0.01, * * p<0.05, * p<0.1$. $\mid$ Residuals $s_{i j t} \mid$ measures the deviance residual of the baseline logistic regression and measures the disagreement between the maxima of the observed and the fitted log likelihood functions. 


\subsection{List of countries included in the counterfactuals}

Table ST2 - False Negatives by Period and Country (Number)

\begin{tabular}{|c|c|c|c|c|c|}
\hline \multicolumn{2}{|c|}{$1995-2001$} & \multicolumn{2}{|c|}{$2002-2007$} & \multicolumn{2}{|c|}{$2008-2014$} \\
\hline SDN(18) & $\overline{\mathrm{KHM}(2)}$ & $\mathrm{CHL}(37)$ & AUT(1) & PER(36) & $\operatorname{IDN}(4)$ \\
\hline ZAF(15) & MOZ(2) & MEX(16) & BEL(1) & $\operatorname{coL}(29)$ & MYS(4) \\
\hline EGY (14) & MWI(2) & USA(12) & $\mathrm{BHR}(1)$ & FJI(27) & $\operatorname{NLD}(4)$ \\
\hline $\operatorname{MAR}(12)$ & $\mathrm{PHL}(2)$ & ZAF(11) & CAN(1) & HTI(27) & $\operatorname{VNM}(4)$ \\
\hline MEX(11) & PRT(2) & $\operatorname{MLT}(9)$ & $\operatorname{DEU}(1)$ & $\operatorname{KOR}(20)$ & $\mathrm{CHE}(3)$ \\
\hline TUN(11) & $\operatorname{RUS}(2)$ & JOR(8) & DNK(1) & TTO(19) & CHL(3) \\
\hline $\operatorname{IRQ}(8)$ & SUR(2) & $\mathrm{CHN}(6)$ & $\operatorname{ESP}(1)$ & $\mathrm{BGR}(11)$ & ISL(3) \\
\hline MDA(8) & SWE(2) & CYP(5) & FIN (1) & CYP(11) & PHL(3) \\
\hline $\operatorname{ARE}(7)$ & BRA(1) & ISL(5) & $\mathrm{FRA}(1)$ & $\operatorname{HRV}(11)$ & USA(3) \\
\hline $\operatorname{BLR}(7)$ & $\mathrm{CHL}(1)$ & LKA(5) & $\operatorname{GBR}(1)$ & $\operatorname{ROM}(11)$ & BRN (2) \\
\hline $\operatorname{MUS}(7)$ & CRI(1) & LTU(5) & GRC(1) & AUT(10) & NOR(2) \\
\hline $\operatorname{OMN}(7)$ & $\operatorname{DEU}(1)$ & LVA(5) & GTM(1) & GRC(10) & $\operatorname{PAK}(2)$ \\
\hline QAT(7) & $\operatorname{ESP}(1)$ & MAR(5) & $\operatorname{HRV}(1)$ & CZE(9) & CRI(1) \\
\hline UKR(7) & FRA(1) & NOR(5) & ISR(1) & HUN(9) & $\operatorname{JOR}(1)$ \\
\hline JOR(6) & $\mathrm{GAB}(1)$ & PAK(5) & ITA(1) & IND(9) & OMN(1) \\
\hline LBN(6) & $\operatorname{GBR}(1)$ & EGY(4) & $\operatorname{JPN}(1)$ & LVA(9) & PAN(1) \\
\hline $\mathrm{BHR}(5)$ & $\operatorname{HUN}(1)$ & $\mathrm{KOR}(4)$ & $\mathrm{KHM}(1)$ & NZL(9) & TUR(1) \\
\hline LAO(5) & ISL(1) & AUS(3) & $\mathrm{LAO}(1)$ & POL(9) & \\
\hline $\operatorname{BRN}(4)$ & $\operatorname{ITA}(1)$ & $\mathrm{BGD}(3)$ & $\operatorname{MDA}(1)$ & AUS(8) & \\
\hline ISR(4) & MYS(1) & BGR(3) & NLD $(1)$ & DNK(8) & \\
\hline KWT(4) & $\operatorname{NLD}(1)$ & BRN(3) & $\operatorname{PAN}(1)$ & FIN(8) & \\
\hline $\operatorname{SAU}(4)$ & NZL(1) & $\mathrm{CHE}(3)$ & PRT(1) & JPN(8) & \\
\hline TJK(4) & $\mathrm{POL}(1)$ & CRI(3) & SWE(1) & $\operatorname{SVN}(8)$ & \\
\hline AZE(3) & $\operatorname{VEN}(1)$ & CZE(3) & SYR(1) & BEL(7) & \\
\hline $\mathrm{BOL}(3)$ & VNM(1) & HTI(3) & & $\mathrm{BRB}(7)$ & \\
\hline GEO(3) & & HUN(3) & & $\operatorname{LTU}(7)$ & \\
\hline IDN(3) & & IND(3) & & $\operatorname{MLT}(7)$ & \\
\hline KAZ(3) & & NPL(3) & & $\operatorname{PRT}(7)$ & \\
\hline KGZ(3) & & NZL(3) & & $\operatorname{SVK}(7)$ & \\
\hline MDG(3) & & POL(3) & & SWE(7) & \\
\hline SYR(3) & & SVK(3) & & FRA(6) & \\
\hline AUT(2) & & $\operatorname{SVN}(3)$ & & IRL(6) & \\
\hline BEL(2) & & $\mathrm{DZA}(2)$ & & ITA(6) & \\
\hline $\operatorname{CAN}(2)$ & & $\mathrm{HND}(2)$ & & DEU(5) & \\
\hline $\operatorname{COG}(2)$ & & $\operatorname{IRL}(2)$ & & $\operatorname{ESP}(5)$ & \\
\hline DNK(2) & & $\operatorname{LBN}(2)$ & & $\mathrm{KHM}(5)$ & \\
\hline FIN(2) & & ROM(2) & & LAO(5) & \\
\hline GRC(2) & & $\operatorname{SLV}(2)$ & & CAN(4) & \\
\hline $\operatorname{IRL}(2)$ & & SUR(2) & & $\mathrm{CHN}(4)$ & \\
\hline $\operatorname{KEN}(2)$ & & $\mathrm{THA}(2)$ & & GBR(4) & \\
\hline
\end{tabular}

List of countries included in the structural gravity counterfactual (estimation sample, $\mathrm{N}=111$ ). In computing the counterfactual analysis we will consider Germany (DEU) as the benchmark country. 
Table ST3 - China Optimal Trade Partners

\begin{tabular}{|c|c|c|}
\hline 1995-2001 & 2002-2007 & $2008-2014$ \\
\hline KOR(0.182) & KOR(0.345) & KOR(0.435) \\
\hline JPN(0.117) & $\mathrm{HKG}(0.19)$ & JOR(0.361) \\
\hline MNG(0.09) & JPN(0.171) & $\operatorname{ISR}(0.278)$ \\
\hline MYS(0.077) & VNM(0.158) & JPN(0.255) \\
\hline $\operatorname{SGP}(0.074)$ & ТНА(0.15) & MNG(0.239) \\
\hline PHL(0.073) & PHL(0.137) & SYR(0.217) \\
\hline THA(0.073) & $\operatorname{IDN}(0.115)$ & FIN(0.198) \\
\hline $\operatorname{BGD}(0.069)$ & MYS(0.109) & $\operatorname{DEU}(0.181)$ \\
\hline PAK(0.066) & MNG(0.105) & $\operatorname{SWE}(0.176)$ \\
\hline VNM(0.066) & IND(0.1) & NLD(0.163) \\
\hline IND(0.065) & $\operatorname{GBR}(0.099)$ & POL(0.163) \\
\hline IDN(0.064) & $\operatorname{DEU}(0.097)$ & $\operatorname{GBR}(0.162)$ \\
\hline SYR(0.064) & FRA(0.096) & FRA(0.154) \\
\hline $\operatorname{MMR}(0.063)$ & & ITA(0.15) \\
\hline DEU(0.062) & & ISL(0.145) \\
\hline \multirow[t]{17}{*}{ RUS(0.061) } & & GRC(0.144) \\
\hline & & DNK(0.144) \\
\hline & & $\operatorname{ROM}(0.141)$ \\
\hline & & $\mathrm{CHE}(0.139)$ \\
\hline & & CYP(0.134) \\
\hline & & $\operatorname{AUT}(0.134)$ \\
\hline & & EGY(0.133) \\
\hline & & TUR(0.132) \\
\hline & & $\operatorname{MAR}(0.131)$ \\
\hline & & $\operatorname{MEX}(0.131)$ \\
\hline & & $\operatorname{HUN}(0.129)$ \\
\hline & & IRL(0.128) \\
\hline & & OMN(0.128) \\
\hline & & $\operatorname{MLT}(0.128)$ \\
\hline & & BEL(0.126) \\
\hline & & $\operatorname{PRT}(0.125)$ \\
\hline & & $\operatorname{ESP}(0.125)$ \\
\hline
\end{tabular}

We consider as optimal trade partners for China the country pairs with a probability above the relevant threshold in each period, estimated using the Panel Logit model in Equation 1. In computing the counterfactual analysis we will consider Germany (DEU) as the benchmark country. List of countries included in the structural gravity counterfactual (estimation sample, $\mathrm{N}=111$ ). Regional Comprehensive Economic Partnership (RCEP) countries are in bold. 
Table ST4 - Weighted Average General Equilibrium effects of RTAs shock $(\sigma=7)$

\begin{tabular}{|c|c|c|c|c|}
\hline & \multicolumn{2}{|c|}{ False Negatives, FNAll } & \multicolumn{2}{|c|}{ False Positives, FPCHN } \\
\hline & Untreated & Treated & Untreated & Treated \\
\hline$\Delta$ Export $_{1994}^{95-01}$ & 0.037 & -0.324 & -0.197 & 4.531 \\
\hline$\Delta$ Export $_{2002}^{02-07}$ & 0.284 & -0.699 & -0.229 & 5.124 \\
\hline$\Delta$ Export $_{2006}^{08-14}$ & 0.194 & -0.857 & -0.178 & 5.227 \\
\hline$\Delta \mathrm{GDP}_{1994}^{95-01}$ & 0.001 & -0.021 & -0.016 & 0.279 \\
\hline$\Delta \mathrm{GDP}_{2002}^{02-07}$ & 0.043 & -0.044 & -0.025 & 0.348 \\
\hline$\Delta \mathrm{GDP}_{2006}^{08-14}$ & 0.019 & -0.040 & -0.038 & 0.326 \\
\hline
\end{tabular}

Results from separate cross-sectional regressions: subscript indicates the year of the observed trade flow, superscript the period of RTA shocks. Baseline Real GDPs are used as weights. 